MARINA ROCHA PINTO PORTELA NUNES

\title{
UM NOVO ALGORITMO PARA MODELAGEM DE MECÂNICA DA FRATURA USANDO O MÉTODO DOS ELEMENTOS DE CONTORNO
}


MARINA ROCHA PINTO PORTELA NUNES

\section{UM NOVO ALGORITMO PARA MODELAGEM DE MECÂNICA DA FRATURA USANDO O MÉTODO DOS ELEMENTOS DE CONTORNO}

Dissertação apresentada à Escola Politécnica da Universidade de São Paulo como parte dos requisitos para obtenção do título de Mestre em Engenharia de Estruturas. 


\section{UM NOVO ALGORITMO PARA MODELAGEM DE MECÂNICA DA FRATURA USANDO O MÉTODO DOS ELEMENTOS DE CONTORNO}

Dissertação apresentada à Escola Politécnica da Universidade de São Paulo como parte dos requisitos para obtenção do título de Mestre em Engenharia de Estruturas.

Área de concentração:

Engenharia de Estruturas.

Orientador:

Prof. Dr. Marcos Aurélio Marques Noronha. 
FICHA CATALOGRÁFICA 
Aos meus pais pelo apoio e incentivo de sempre. 


\section{AGRADECIMENTOS}

A Deus por ter me dado saúde e paz para realizar mais uma etapa importante em minha vida.

A minha mãe pelo amor e incentivo para que eu seguisse o caminho para me tornar uma pessoa digna.

Ao meu pai pelo amor e apoio.

A minha tia Ceiça pela amizade e carinho.

Ao Julien pela dedicação, amor, paciência e respeito, sempre me apoiando em todos os momentos.

A minha querida amiga Eliane, pela amizade, paciência e apoio.

Ao professor Marcos Noronha pela amizade e por seus ensinamentos.

Aos meus amigos do LMC, que tornaram a realização deste trabalho mais agradável, pela boa convivência, pelos assuntos discutidos, pelo conhecimento trocado, pela amizade.

À FAPESP (Fundação de Amparo à Pesquisa do Estado de São Paulo) pelo apoio financeiro imprescindível ao desenvolvimento deste trabalho. 


\section{RESUMO}

Este trabalho trata da análise de problemas da Mecânica da Fratura Elástica Linear (MFEL) utilizando o Método dos Elementos de Contorno (MEC). Esse método constitui uma poderosa e precisa técnica de análise numérica. A necessidade da discretização somente do contorno do modelo é um dos grandes atrativos do MEC. Na Mecânica da Fratura, o MEC é adequado pela própria natureza de sua formulação, a qual está baseada em soluções fundamentais. Dentre os parâmetros da MFEL, destaca-se o Fator de Intensidade de Tensão (FIT). No presente desenvolvimento, esse parâmetro é analisado numericamente pela técnica da correlação dos deslocamentos e por uma técnica alternativa a qual emprega o campo de tensões presente na extremidade da trinca. A direção do crescimento da trinca é analisada por meio do critério da Máxima Tensão Circunferencial. Os resultados obtidos são comparados à solução analítica e a outros resultados encontrados na literatura.

Palavras-chave: Mecânica da Fratura Elástica Linear, Método dos Elementos de Contorno, Fator de Intensidade de Tensão. 


\begin{abstract}
This work deals with the analysis of Linear Elastic Fracture Mechanics (LEFM) problems using the Boundary Element Method (BEM). This method is a powerful and accurate technique of numerical analysis. The need of discretization only of the boundary of the model is one of the major advantageous features of the BEM. In Fracture Mechanics, the BEM is adequate due to its intrinsic formulation, which is based on fundamental solutions. In the LEFM, the Stress Intensity Factors (SIF) is one of the most important parameters. In the present study, this parameter is numerically analyzed by the correlation displacement technique and by an alternative technique which considers the stress field at the crack tip. The direction of the crack growth is analyzed using the criterion of Maximum Circumferential Stress. The results are compared to the analytical solution and to other results of literature.
\end{abstract}

Keywords: Linear Elastic Fracture Mechanics, Boundary Element Method, Stress Intensity Factor. 


\section{SUMÁRIO}

RESUMO

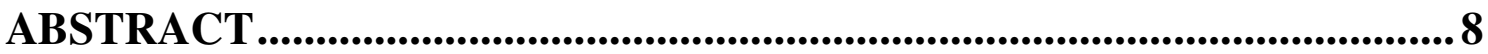

1 INTRODUÇÃO ............................................................................................ 11

1.1 Justificativa e importância do tema............................................................................ 11

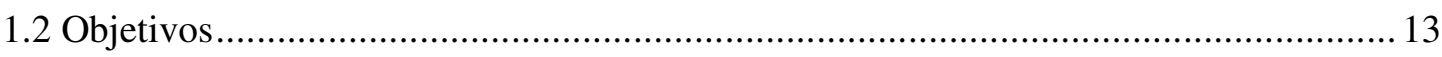

2 EVOLUÇÃO HISTÓRICA ....................................................................15

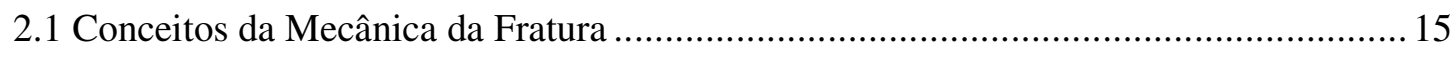

2.2 Modelagem de Mecânica da Fratura usando oMEC .................................................... 18

3 TEORIA DA ELASTICIDADE LINEAR ..............................................20

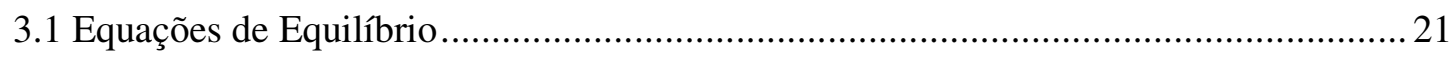

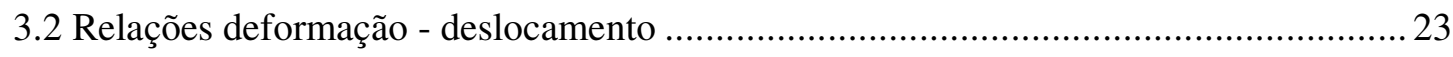

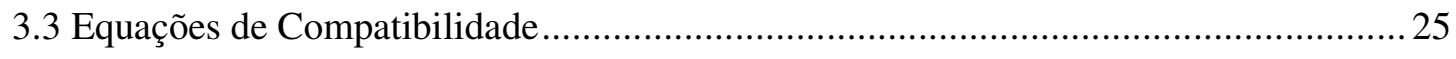

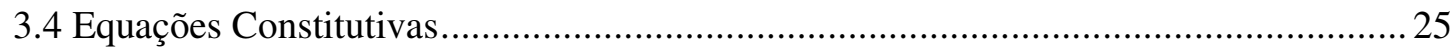

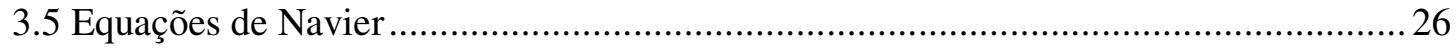

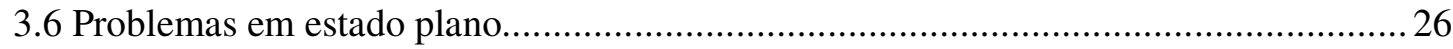

4 MECÂNICA DA FRATURA ELÁSTICA LINEAR .....................................28

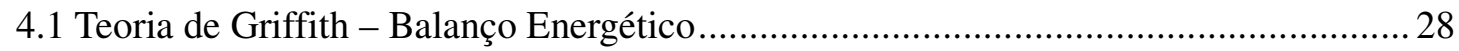

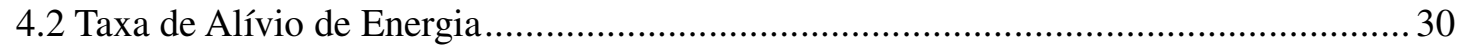

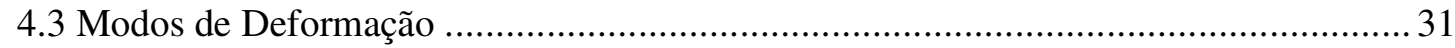

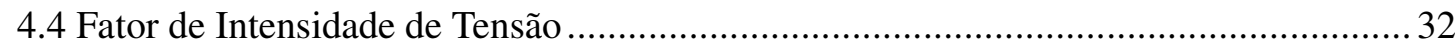

4.5 Relação Campo de Tensão e Fator de Intensidade de Tensão...................................... 33

5 MÉTODO DOS ELEMENTOS DE CONTORNO..................................36

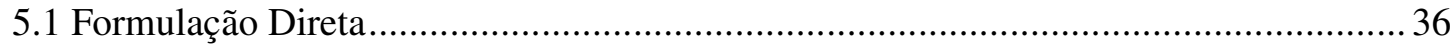

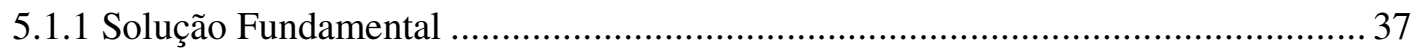

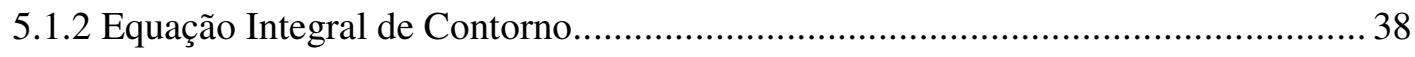

5.1.2.1 Equação Integral para pontos do domínio.................................................... 38

5.1.2.2 Equação Integral para pontos do contorno................................................ 40

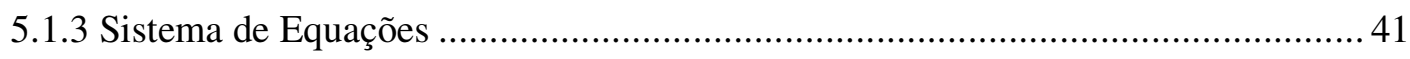

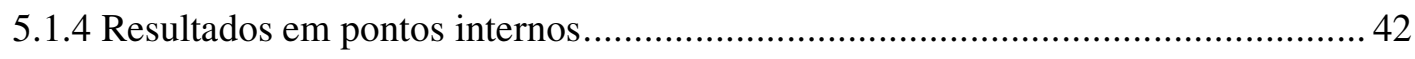

5.2 Técnica de Integração para Resolução das Integrais Quase Singulares ......................... 43 


\section{CONSIDERAÇÕES SOBRE A IMPLEMENTAÇÃO}

COMPUTACIONAL_.....................................................................................4

6.1 Técnicas numéricas para obtenção do Fator de Intensidade de Tensão .........................47

6.1.1 Técnica de Correlação dos Deslocamentos............................................................. 48

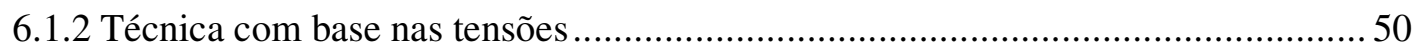

6.2 Direção de Propagação da Trinca............................................................................. 51

6.2.1 Critério da Máxima Tensão Circunferencial ......................................................... 52

6.2.2 Metodologia para análise da direção de propagação da trinca ............................ 53

7 RESULTADOS NUMÉRICOS ...............................................................55

7.1 Determinação do Fator de Intensidade de Tensão....................................................... 55

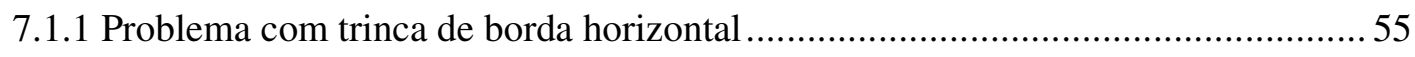

7.1.1.1 Técnica de Correlação dos Deslocamentos .................................................58

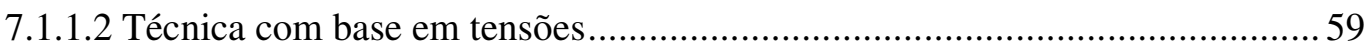

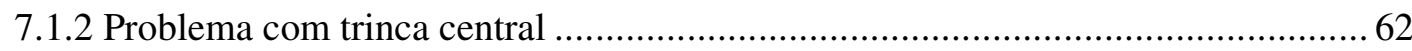

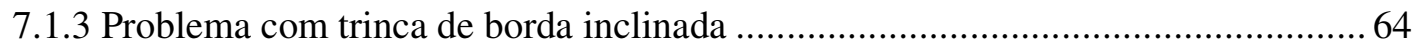

7.2 Determinação da direçãode crescimento da trinca...................................................6 67

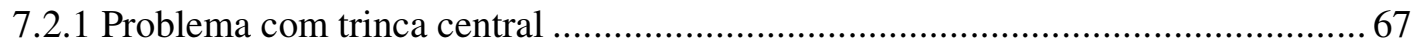

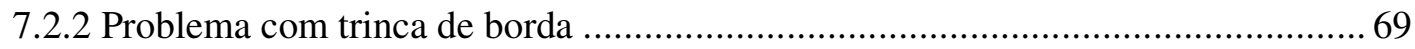

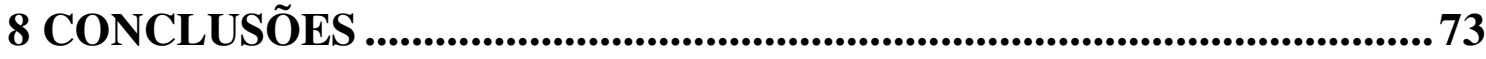

9 REFERÊNCIAS BIBLIOGRÁFICAS ..................................................... 74 


\section{INTRODUÇÃO}

As rupturas catastróficas em estruturas de engenharia, ocorridas no século $\mathrm{XX}$, impulsionaram o estudo do comportamento de materiais, como o aço, dando origem à Mecânica da Fratura.

Os estudos em Mecânica da Fratura resultaram em novas concepções de projetos, assumindo a estrutura não como um meio contínuo, mas apresentando falhas concentradoras de tensões.

Nas últimas décadas, os métodos numéricos têm tido larga aplicação na Mecânica da Fratura. O Método dos Elementos de Contorno (MEC), ferramenta numérica alternativa ao Método dos Elementos Finitos (MEF), pode ser utilizado na análise de problemas que apresentam concentrações de tensões, principalmente no caso de fraturas, onde o emprego de soluções singulares como ponderadora pode simular a presença de singularidades na ponta da trinca com maior precisão.

O presente trabalho prevê a modelagem de trinca discreta utilizando uma avançada técnica de integração no MEC. Esse estudo foi implementado numa plataforma computacional do grupo do professor Marcos Noronha, sendo usada linguagem de programação orientada a objeto.

\subsection{Justificativa e importância do tema}

Com o avanço da tecnologia computacional e o amplo uso de técnicas numéricas, uma grande variedade de métodos computacionais foi desenvolvida, como por exemplo, o Método das Diferenças Finitas, o Método dos Elementos Finitos e o Método dos Elementos de Contorno. Atualmente, a utilização do Método dos Elementos de Contorno em problemas 
de Mecânica da Fratura apresenta-se como uma rica área de pesquisa com vários pontos importantes a serem estudados.

A Mecânica da Fratura é um ramo das ciências mecânicas que tenta quantificar as condições sob as quais uma estrutura, submetida a um carregamento, pode entrar em colapso devido à propagação de uma trinca presente nesta estrutura.

Vários acidentes catastróficos ocorreram ao longo da história envolvendo problemas da Mecânica da Fratura. Como exemplo pode-se citar o desabamento da ponte de ferro fundido de Michigan em 1876, a ruptura de um tanque de gás natural liquefeito em Cleveland em 1944, a ruptura catastrófica de navios de carga (Liberty ships) usados na Segunda Guerra Mundial, a queda dos aviões Comets de 1953 a 1954, o desabamento da ponte Silver Bridge ligando o estado de Virginia a Ohio em 1967.

Devido aos desastres ocorridos, houve a necessidade de quantificar e qualificar os fenômenos de ruptura das estruturas, constantemente imprevisíveis, motivando o aprimoramento de técnicas práticas de ensaios e definições teóricas correlatas à Mecânica da Fratura.

No Brasil, a presença de trincas nas estruturas provoca gastos ainda desconhecidos. Nos Estados Unidos, de acordo com Saouma (2000), o custo da existência de trincas nos materiais, insumo da indústria, é de aproximadamente 120 bilhões de dólares por ano, ou estimado em $4 \%$ do produto nacional bruto dos EUA em 2000. Ainda neste trabalho afirma-se que seria possível reduzir esses custos em torno de 35 bilhões usando apenas as tecnologias disponíveis e mais de 28 bilhões poderiam ser economizados se novas pesquisas fossem realizadas na prevenção dos efeitos danosos das trincas. Com base nesses valores, é possível perceber a importância e o interesse que o assunto desperta na comunidade internacional.

Com o desenvolvimento computacional e a aplicação dos métodos numéricos para estudo de problemas da Mecânica da Fratura obteve-se uma melhora considerável na precisão dos cálculos dos parâmetros utilizados para estudo das trincas. Como exemplo pode-se citar o Fator de Intensidade de Tensão (FIT ou $K$ ), o qual tornou-se facilmente calculável com a aplicação do Método dos Elementos Finitos (MEF) e, posteriormente, do Método dos Elementos de Contorno (MEC), entre outros métodos. 
O MEC tem-se mostrado uma alternativa viável ao estudo de diversos problemas de engenharia, em especial na análise de problemas envolvendo concentração de tensão, os quais são particularmente importantes na ponta da trinca.

O MEC é uma técnica numérica baseada na resolução de equações integrais de contorno que governam um problema, discretizando-se apenas o contorno deste problema. Essa característica conduz a uma redução considerável do sistema de equações envolvido e do volume de dados de entrada comparada a outros métodos numéricos. Apesar dessas vantagens, as matrizes resultantes das integrações sobre os elementos no contorno são densas e não simétricas.

Nessa dissertação é apresentada uma formulação do MEC para análise bidimensional de problemas com trinca discreta, a qual apresenta uma separação entre suas faces (abertura) muito pequena comparada ao seu comprimento. Essa característica leva ao surgimento de integrais quase singulares, podendo gerar erros numéricos na solução do problema em estudo, caso essas integrais não sejam tratadas adequadamente.

No entanto, esse trabalho emprega uma técnica de integração no MEC, desenvolvida por Dumont e Noronha (1998) que resolve essas integrais quase singulares de forma precisa, mantendo a estabilidade numérica do problema. Resolvidas essas integrais e obtidas a solução no contorno são apresentadas metodologias para a análise da trinca discreta aplicando conceitos da Mecânica da Fratura Elástica Linear (MFEL).

\subsection{Objetivos}

Este trabalho tem como objetivo principal a modelagem bidimensional da trinca discreta utilizando o MEC. $\mathrm{Na}$ análise dos problemas com trinca discreta têm-se como objetivos:

- Utilizar a técnica de integração desenvolvida por Dumont e Noronha (1998) para resolver o problema da singularidade presente na formulação do MEC. Esta técnica 
permite o cálculo de forma precisa sem a necessidade de discretizações finas na região próxima à ponta da trinca;

- Determinar o Fator de Intensidade de Tensão (FIT) na ponta da trinca;

- Avaliar a direção da propagação da trinca;

- Comparar os resultados obtidos com soluções analíticas e referências encontradas na literatura. 


\section{EVOLUÇÃO HISTÓRICA}

Neste capítulo são relatados de forma sucinta os principais trabalhos relacionados ao desenvolvimento desta dissertação. É apresentada uma revisão sobre os conceitos da Mecânica da Fratura, principalmente o FIT e, em seguida, é feita uma breve apresentação sobre a modelagem de Mecânica da Fratura usando o Método dos Elementos de Contorno (MEC).

\subsection{Conceitos da Mecânica da Fratura}

Os primeiros registros históricos relacionados ao estudo do problema da falha de materiais remontam à segunda metade do século XV com alguns experimentos de Leonardo da Vinci. Nestes estudos, Da Vinci chegou a resultados que mostravam a resistência de arames de um mesmo material variava inversamente ao comprimento do fio. Leonardo da Vinci interpretou que este comportamento estava ligado ao fato de que a probabilidade de se encontrar defeitos internos em um fio longo é maior (ANDERSON, 1995).

Em 1913, Inglis quantificou os efeitos da concentração de tensões ao analisar orifícios elípticos em placas planas (BROEK, 1989). Inglis obteve uma expressão que determina a tensão na extremidade do maior eixo da elipse e verificou que o efeito da concentração de tensões é maior quanto menor for o raio de curvatura da elipse. No entanto, quando este raio tende a zero, a elipse aproxima-se geometricamente de uma trinca com faces coincidentes e a tensão tende ao infinito. Isto sugere que a ruptura ocorra numa tensão nominal aplicada próxima de zero o que não acontece na realidade. Inglis não conseguia então explicar porque as peças quebravam.

Em 1920, Griffith sugeriu que as falhas internas agiam como intensificadores de tensão afetando a resistência dos sólidos. Além disso, formulou o critério termodinâmico para a fratura, o qual considera a mudança total na energia que acontece durante o processo de 
fratura. Com a propagação da trinca, a energia potencial é liberada e transferida para a formação de novas superfícies de trinca (BROEK, 1989).

Após os estudos realizados por Griffith, a Mecânica da Fratura permaneceu praticamente inalterada por aproximadamente vinte anos. Em 1939, Westergaard formulou a expressão para o campo de tensão nas proximidades da ponta da trinca (BROEK, 1989). Até então, a Mecânica da Fratura era, relativamente, uma ciência obscura e puramente empírica.

Entretanto, um grande número de fraturas catastróficas ocorridas durante e logo após a Segunda Guerra Mundial motivaram um desenvolvimento impetuoso da Mecânica da Fratura. Na indústria naval, por exemplo, vários acidentes foram registrados, principalmente a partir do surgimento de estruturas soldadas. Mais de 1.000 navios construídos durante a guerra sofreram danos estruturais, com 150 sendo gravemente avariados e 10 separados totalmente em duas partes.

Após a guerra, Irwin utilizou as idéias de Griffith e propôs os fundamentos da Mecânica da Fratura (SAOMA, 2000). Irwin estendeu a teoria de Griffith para metais passando então a considerar materiais capazes de sofrer deformação plástica e alterou a solução geral de Westergaard, introduzindo o conceito de Fator de Intensidade de Tensão (FIT ou $K)$.

O FIT permite avaliar a resistência da estrutura à fratura e varia em função da estrutura e do carregamento a qual está submetida, podendo ser determinado a partir do conhecimento do estado tensional bem como da abertura da trinca.

As tensões nos pontos próximos à ponta da trinca relacionam-se na razão inversa da raiz quadrada do raio, definido como a distância desses pontos à extremidade da trinca. Assim sendo, pode-se observar que existe nas proximidades da ponta da trinca uma região bastante singular, pois à medida que o raio diminui, as tensões tendem a infinito.

Além de introduzir o conceito do Fator de Intensidade de Tensão, Irwin verificou e comprovou a taxa de energia liberada $G$. As relações estudadas entre $K$ e $G$ foram a base para o aparecimento da Mecânica da Fratura Elástica Linear (EWALDS e WANHILL, 1984).

Considerações não-lineares foram propostas por Wells e Rice (BROEK, 1986). Em 1961, a partir de ensaios de fraturamento para obtenção de $K_{I C}$ (tenacidade ao fraturamento) para aços estruturais, Wells observou que as faces da trinca se afastavam. Essa 
separação entre as faces da trinca foi chamada de abertura de ponta de trinca $\delta$ (CTOD Crack Tip Opening Displacement).

Em 1968, Rice introduziu o conceito da integral-J, uma integral de linha de contorno independente do percurso, que corresponde à taxa de mudança de energia potencial para um sólido elástico não-linear durante a extensão unitária da trinca (BROEK, 1989).

Em meados dos anos 60, Erdogan \& Sih introduziram o primeiro modelo de propagação de trincas para o modo misto de deformação. Grandes contribuições, em muito maior número, aconteceram com a introdução dos métodos numéricos para a análise de estruturas trincadas (SAOUMA, 2000).

Nas últimas décadas, a Mecânica da Fratura ganhou um novo impulso com o uso dos métodos numéricos para estudo de estruturas trincadas. Os métodos numéricos são utilizados na Mecânica da Fratura para o cálculo do FIT e para simular a propagação de trincas em materiais.

Dentre os métodos numéricos mais utilizados na Mecânica da Fratura, o MEF tem tido a preferência dos pesquisadores (BITTENCOURT, 1993). Entretanto, outro método bastante versátil e poderoso vem ganhando destaque na comunidade científica. Este método é conhecido como Método dos Elementos de Contorno (MEC).

Um dos problemas enfrentados pelos métodos numéricos para a obtenção precisa do FIT é a representação das singularidades na ponta da trinca. O MEC é vantajoso em problemas envolvendo singularidades, como os de propagação de trincas, pois as formulações requerem pouca discretização, há uma pequena modificação na malha com o crescimento da trinca e a aproximação necessária das variáveis é pouco significativa. Entretanto, o MEC apresenta desvantagens quanto as suas matrizes densas e não simétricas.

Nas últimas décadas, muitas técnicas de integração foram sugeridas para o tratamento das integrais singulares. Nesse contexto, os pesquisadores Dumont e Noronha (1998) desenvolveram uma sistemática para analisar as integrais singulares e quase singulares. Nessa técnica proposta pelos dois pesquisadores, inicialmente é necessário determinar a parcela efetiva de singularidade ou quase-singularidade e a parcela regular da integral original. Depois, a técnica é então aplicada para a regularização da integral por meio do desenvolvimento da parcela regular do integrando em torno do pólo (real ou complexo) 
que está sendo analisado. Este procedimento é feito utilizando-se a divisão sintética de polinômios (DSP).

Esta técnica é eficiente para a análise bidimensional com o MEC, apresentando a grande vantagem de oferecer ganho de precisão para funções de singularidade cada vez mais fortes, enquanto a maioria das técnicas existentes mostra um comportamento inverso.

Neste trabalho, a técnica de integração de Dumont e Noronha (1998) é utilizada para tratar as integrais singulares em problemas de trinca discreta usando o MEC.

\subsection{Modelagem de Mecânica da Fratura usando o MEC}

$\mathrm{Na}$ literatura, encontra-se uma grande quantidade de trabalhos importantes sobre o desenvolvimento de formulações do MEC em problemas de Mecânica da Fratura. Será apresentado um breve histórico a respeito do assunto.

Os primeiros trabalhos que tratavam do problema da análise de trincas são da década de 70, de autoria de Cruse e Van Buren (1971). Neste trabalho os autores avaliaram o campo de tensões nas proximidades da trinca em modelos elásticos tridimensionais.

Cruse (1972) analisou modelos bi e tridimensionais considerando a trinca de forma elíptica. Essa técnica levou a erros significativos, exigindo ainda um grande número de elementos para aproximar as variáveis da superfície da trinca.

O trabalho de Cruse teve continuidade e, em 1975, propôs uma formulação com base nas funções de Green (SNYDER e CRUSE, 1975). As funções de Green representavam a solução exata de um domínio infinito com a presença da trinca que se pretendia analisar. Com essa técnica os termos integrais referentes ao contorno da trinca desapareciam e a solução era extremamente precisa. Entretanto, sua aplicação era restrita, pois permitia o estudo dos FIT, mas não possibilitava a análise do avanço da trinca como apresenta Telles e Guimarães (2000) e Telles et al. (2005). 
O uso da equação singular, equação integral de deslocamentos, para o estudo de trincas surgiu posteriormente no trabalho de Blandford et al. (1981), utilizando a técnica das sub-regiões para simular o crescimento da trinca entre dois contornos.

A formulação singular também foi utilizada para modelagem de fraturamento coesivo por Cen e Maier (1992) e Liang e Li (1991).

O modelo de sub-regiões foi bastante utilizado para a análise de trincas, mas apresentava o mesmo problema computacional do Método dos Elementos Finitos. Havia a necessidade de se fazer uma previsão do crescimento da superfície com a definição de uma interface e depois modificar a malha em função da resposta obtida.

Outra técnica utilizada na análise de problemas da Mecânica da Fratura baseia-se no uso de equações integrais de deslocamentos e de forças de superfície para nós definidos nas superfícies opostas da trinca. Este estudo encontra-se inicialmente nos trabalhos de Watson (1986) para problemas bidimensionais e no trabalho de Gray et al. (1990).

Atualmente essa técnica é bem difundida e conhecida como o Método dos Elementos de Contorno Dual. Diversos pesquisadores destacam-se nessa área como Portela et al. (2004), Mi (1996), Aliabadi (2002), dentre outros.

Recentemente, alguns trabalhos voltados para a modelagem de trincas usando o MEC, consideraram as faces da trinca muito próximas uma da outra (trinca discreta) e demonstraram que esse modelo é preciso desde que as integrais sobre os elementos presentes na discretização da trinca sejam bem avaliadas. Utilizou-se para tal integração analítica dos termos integrais (MACIEL, 2003) ou sub-elementação adequada (GUILBAULT e LALONDE, 2009). 


\section{TEORIA DA ELASTICIDADE LINEAR}

Uma das características dos materiais sólidos é a capacidade de resistir ou transmitir esforços. A resposta desses materiais aos esforços aplicados está intimamente relacionada com a propriedade do material de se deformar elasticamente ou plasticamente. Nesse sentido, são apresentados conceitos da Teoria da Elasticidade Linear que servirão de base para temas presentes nessa dissertação.

A Teoria da Elasticidade Linear estuda o campo de tensões, deformações e deslocamentos em sólidos deformáveis. Essa Teoria é válida considerando as seguintes hipóteses:

$>$ O material constituinte do sólido em análise apresenta comportamento elástico linear;

O material é homogêneo, contínuo e isótropo.

As principais relações e hipóteses apresentadas por esta teoria podem ser expressas por meio de três equações: as equações de equilíbrio, as de compatibilidade e as constitutivas. A partir dessas equações podem-se analisar os modelos sólidos deformáveis sujeitos à ação de forças externas.

O modelo constitutivo que representa o comportamento dos materiais em regime elástico é denominado Modelo Elástico de Hooke. Este modelo, representado por uma mola, caracteriza-se pelo aparecimento da deformação elástica instantânea devido à aplicação de uma solicitação estática (Figura 3.1).

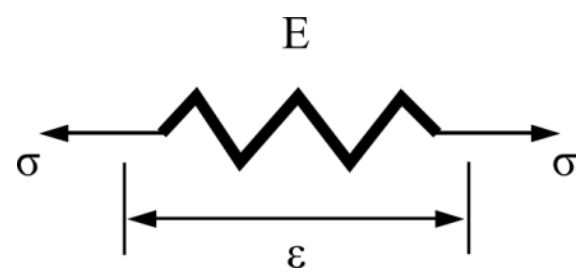

Figura 3.1: Modelo elástico de Hooke. 
A relação constitutiva geral num modelo elástico pode ser escrita pela expressão $\sigma_{i j}=C_{i j}^{l m} \varepsilon_{l m}$ onde $\sigma_{i j}$ e $\varepsilon_{l m}$ são os tensores de tensão e de deformação respectivamente, e $C_{i j}^{l m}$ o tensor constitutivo que os relaciona.

\subsection{Equações de Equilíbrio}

As equações de equilíbrio resultam da análise de forças externas que atuam em elementos infinitesimais extraídos de um sólido em estudo. As forças atuantes sobre um corpo, importantes para essa análise, podem ser classificadas em forças de volume e forças de superfície. As forças de volume atuam sobre os elementos de volume ou de massa dentro do corpo, isto é, correspondem às forças gravitacionais e são determinadas por unidades de volume. As forças de superfície atuam sobre o contorno da superfície do corpo e são determinadas por unidade de área da superfície transversal na qual atuam.

Considere um sólido deformável submetido à ação de forças de volume e de superfície como mostra a Figura 3.2.

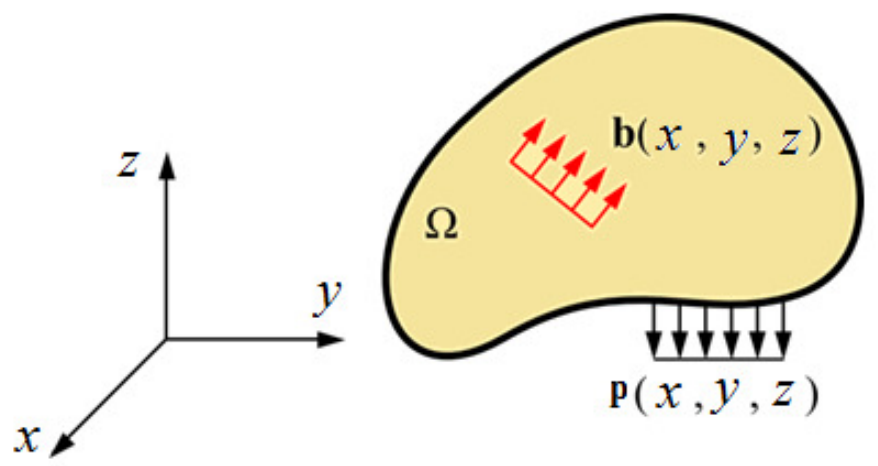

Figura 3.2: Sólido submetido a forças de volume e de superfície.

Seja agora um elemento cúbico infinitesimal representando um ponto $\mathbf{P}$ qualquer do sólido. As componentes de tensão atuantes nas faces desse elemento estão representadas na Figura 3.3. 


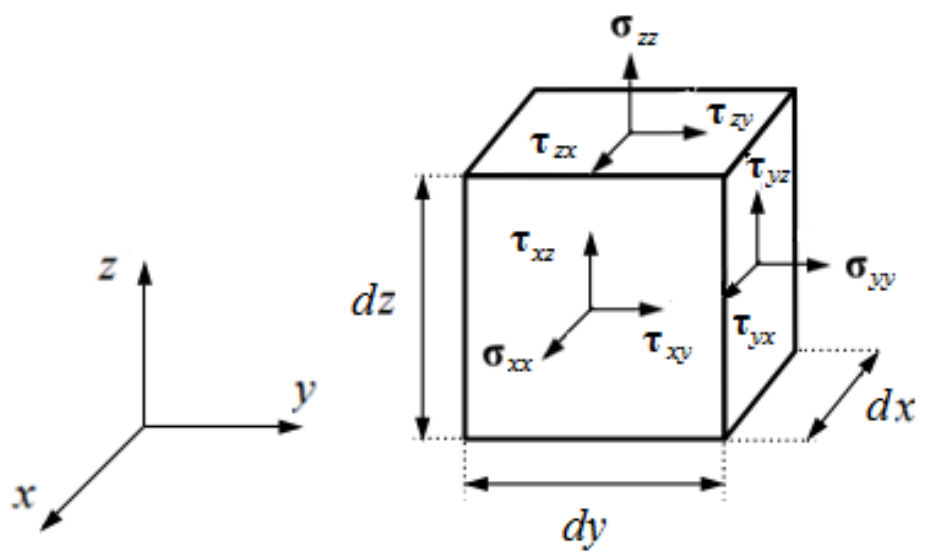

Figura 3.3: Componentes de tensões atuantes num elemento infinitesimal (TIMOSHENKO, 1980).

O estado de tensões de um ponto $\mathbf{P}$ qualquer do sólido é definido por:

$$
\boldsymbol{\sigma}=\left[\begin{array}{lll}
\sigma_{x x} & \tau_{x y} & \tau_{x z} \\
\tau_{y x} & \sigma_{y y} & \tau_{y z} \\
\tau_{z x} & \tau_{z y} & \sigma_{z z}
\end{array}\right],
$$

onde $\boldsymbol{\sigma}$ é o tensor das tensões. O primeiro subscrito, presente nas componentes de tensão, indica a direção normal à face do elemento na qual a componente atua e o segundo subscrito indica o eixo ao qual a componente de tensão é paralela. Conhecido $\boldsymbol{\sigma}$ é possível obter as tensões no ponto $\mathbf{P}$, associadas a qualquer outro plano, passando por este ponto.

O sólido está em equilíbrio se as seguintes condições forem satisfeitas para um ponto qualquer (elemento infinitesimal) deste sólido:

$$
\begin{aligned}
& \frac{\partial \sigma_{x x}}{\partial x}+\frac{\partial \tau_{x y}}{\partial y}+\frac{\partial \tau_{x z}}{\partial z}+b_{x}=0 \\
& \frac{\partial \tau_{y x}}{\partial x}+\frac{\partial \sigma_{y y}}{\partial y}+\frac{\partial \tau_{y z}}{\partial z}+b_{y}=0 \\
& \frac{\partial \tau_{z x}}{\partial x}+\frac{\partial \tau_{z y}}{\partial y}+\frac{\partial \sigma_{z z}}{\partial z}+b_{z}=0
\end{aligned}
$$

Em notação indicial tem-se:

$$
\sigma_{i j, j}+b_{i}=0
$$


O índice após a vírgula, presente na eq. (3.5), indica a direção na qual a componente de tensão é derivada.

A propriedade de simetria é válida aplicando-se o equilíbrio rotacional ao elemento, resultando em:

$$
\sigma_{i j}=\sigma_{j i}
$$

Sendo conhecida cada componente de $\sigma_{i j}$ em um ponto qualquer e aplicando o equilíbrio dos momentos num tetraedro infinitesimal (Figura 3.4), é possível obter a relação entre as componentes do vetor das forças de superfície $\mathbf{p}$ e as componentes de $\sigma_{i j}$. Esta relação é conhecida como fórmula de Cauchy e é dada por:

$$
p_{i}=\sigma_{i j} n_{j}
$$

sendo $n_{j}$ os cossenos diretores do vetor $\mathbf{n}$ normal à superfície do elemento infinitesimal.

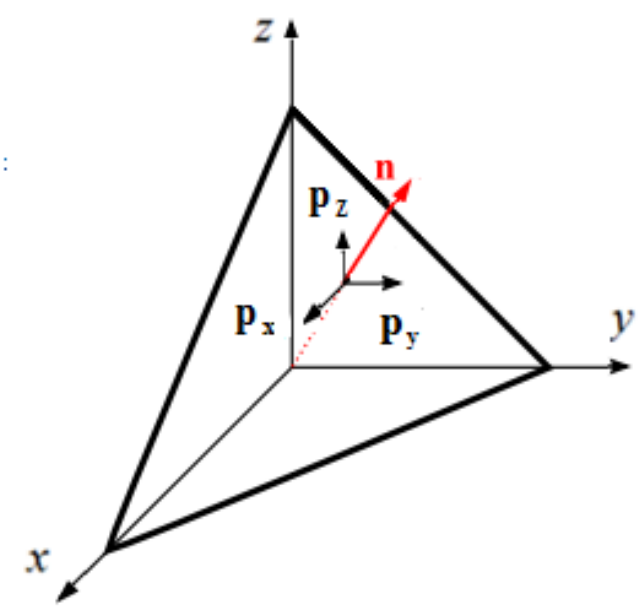

Figura 3.4: Tensões num tetraedro infinitesimal.

\subsection{Relações deformação - deslocamento}

No estudo da deformação de um corpo elástico será considerado que há suficientes restrições para impedir seu deslocamento como corpo rígido, de tal forma que 
nenhum deslocamento de partículas do sólido é possível sem que este sofra uma deformação. Além disso, os conceitos apresentados são válidos para um problema tridimensional e serão consideradas somente pequenas deformações.

Ao sofrer a ação de solicitações externas, um sólido sofre alterações de forma e dimensões, devido aos deslocamentos de suas partículas. O vetor de deslocamento u , para um ponto qualquer desse sólido, é dado por: $\mathbf{u}=\left[\begin{array}{l}u_{x} \\ u_{y} \\ u_{z}\end{array}\right]$.

O estado de deformação em cada ponto do sólido é caracterizado pelo tensor das deformações expresso por:

$$
\boldsymbol{\varepsilon}=\left[\begin{array}{lll}
\varepsilon_{x x} & \varepsilon_{x y} & \varepsilon_{x z} \\
\varepsilon_{y x} & \varepsilon_{y y} & \varepsilon_{y z} \\
\varepsilon_{z x} & \varepsilon_{z y} & \varepsilon_{z z}
\end{array}\right],
$$

sendo válida a relação de simetria $\varepsilon_{i j}=\varepsilon_{j i}$.

É possível obter ainda as relações deformação-deslocamento expressas em notação indicial:

$$
\varepsilon_{i j}=\frac{1}{2}\left(\frac{\partial u_{i}}{\partial x_{j}}+\frac{\partial u_{j}}{\partial x_{i}}\right) \text { ou } \varepsilon_{i j}=\frac{1}{2}\left(u_{i, j}+u_{j, i}\right)
$$

sendo $u_{i, j}$ a derivada do deslocamento da direção $i$ em relação à direção $j$.

A eq. (3.9) relaciona as deformações lineares e angulares de um ponto do sólido com os deslocamentos do mesmo ponto. 


\subsection{Equações de Compatibilidade}

Da mesma forma que o campo de tensões deve atender as equações diferenciais de equilíbrio, o campo de deformações deve obedecer às equações de compatibilidade (ZAGOTTIS, 1983). Estas equações são obtidas a partir das relações deformaçãodeslocamento, eliminando os deslocamentos por meio de derivações, e resultando em:

$$
\varepsilon_{i j, k l}+\varepsilon_{k l, i j}-\varepsilon_{i k, j l}-\varepsilon_{j l, i k}=0
$$

\subsection{Equações Constitutivas}

As equações constitutivas relacionam tensões com deformações, baseando-se em observações experimentais. Estas equações levam em consideração os parâmetros do material do sólido em análise sendo também conhecidas por Lei de Hooke Generalizada. Para materiais elásticos lineares estas equações são expressas por:

$$
\sigma_{i j}=\lambda \delta_{i j} \varepsilon_{k k}+2 \mu \varepsilon_{i j}
$$

onde $\lambda=\frac{v E}{(1+v)(1-2 v)}$ e $\mu=\frac{E}{2(1+v)}$ são constantes de Lamé, sendo:

E: Módulo de Elasticidade Longitudinal;

$v$ : Coeficiente de Poisson;

$\mu$ : Módulo de Elasticidade Transversal;

$\delta$ : Delta de Kronecker:

$\delta_{i j}= \begin{cases}1, & \text { se } i=j \\ 0, & \text { se } i \neq j .\end{cases}$ 


\subsection{Equações de Navier}

Além dos três conjuntos de equações da Teoria Linear da Elasticidade, as funções $u_{i}, \varepsilon_{i j}$ e $\sigma_{i j}$ devem satisfazer as seguintes condições de contorno:

- Naturais ou Neumann: $p_{i}=\bar{p}_{i}$.

- Essenciais ou Dirichilet: $u_{i}=\bar{u}_{i}$.

Combinando-se as equações de equilíbrio, compatibilidade e constitutivas obtémse as equações de Navier, dadas por:

$$
\left(\frac{1}{1-2 v}\right) u_{j, j l}+u_{l, j j}+\frac{1}{\mu} b_{l}=0 .
$$

Estas equações correspondem às equações de equilíbrio expressas em termos das componentes de deslocamento e governam os problemas da Elasticidade Linear.

\subsection{Problemas em estado plano}

O equacionamento de problemas elásticos pode ser simplificado dependendo da geometria do corpo e das condições de contorno aplicadas no problema a ser analisado. A simplificação de problemas tridimensionais em problemas bidimensionais origina os problemas ditos estados planos, os quais podem ser divididos em estados planos de tensão e estados planos de deformação.

Os problemas em Estado Plano de Tensão (EPT) ocorrem quando uma das dimensões (espessura) é muito menor que as demais, sendo o carregamento aplicado no plano médio formado pelas duas maiores dimensões. Nestes casos, admite-se que as tensões na direção da espessura são nulas e que as tensões não nulas são consideradas constantes ao longo da espessura. 
Sendo xy o plano médio formado pelas duas maiores dimensões do corpo, o campo de tensões pode ser representado pelas seguintes componentes $\sigma_{x x}, \sigma_{y y}, \tau_{x y}$. O campo de deformação é caracterizado pelas componentes $\varepsilon_{x x}, \varepsilon_{y y}, \varepsilon_{z z}, \varepsilon_{x y}$. Nesse caso, $\varepsilon_{z z}$ é função das deformações $\varepsilon_{x x}, \varepsilon_{y y}$.

Os problemas em Estado Plano de Deformação (EPD) ocorrem quando o corpo apresenta uma dimensão muito maior que as outras duas e o carregamento é aplicado no plano formado por essas duas dimensões menores. Sendo assim, a deformação na direção da maior dimensão é considerada nula.

Admitindo que $x y$ é o plano que contém os deslocamentos do corpo, as deformações presentes nesse caso são $\varepsilon_{x x}, \varepsilon_{y y}, \varepsilon_{x y}$. O campo de tensões é representado pelas seguintes componentes $\sigma_{x x}, \sigma_{y y}, \sigma_{z z}, \tau_{x y}$, sendo $\sigma_{z z}$ função das tensões $\sigma_{x x}, \sigma_{y y}$. 


\section{MECÂNICA DA FRATURA ELÁSTICA LINEAR}

À medida que o homem passou a adquirir um maior controle tecnológico sobre os materiais, novos sistemas construtivos foram desenvolvidos, surgindo aplicações cada vez mais ousadas. Porém, os materiais utilizados nem sempre apresentavam o comportamento desejado, pois ocorriam falhas inesperadas que levavam as estruturas ao colapso.

Nesse contexto desenvolveu-se a Mecânica da Fratura Elástica Linear (MFEL), a qual se tornou uma poderosa ferramenta para a análise de problemas envolvendo trincas cuja região de comportamento não linear a frente da trinca é desprezível.

Neste capítulo são apresentados conceitos da MFEL necessários para o desenvolvimento desse trabalho.

\subsection{Teoria de Griffith - Balanço Energético}

A primeira análise bem sucedida do comportamento da fratura em elementos trincados foi desenvolvida por Griffith (1920).

Em experimentos realizados, observou-se que imperfeições grandes têm um efeito danoso muito maior nas propriedades dos materiais que as pequenas imperfeições. Naquela época, entretanto, o critério de ruptura usado previa que se as imperfeições fossem geometricamente similares, as concentrações de tensão causadas por essas imperfeições seriam as mesmas, assim como o efeito sobre a resistência dos materiais, independente do tamanho da imperfeição.

Para solucionar essas questões, Griffith desenvolveu um novo critério para previsão da fratura. Sugeriu um modelo que considerasse um balanço de energia baseado não apenas na energia potencial de cargas externas e na energia de deformação elástica 
acumulada, mas também na energia de superfície. Esta energia está associada à criação de uma nova superfície durante o processo de fratura.

Griffith realizou experiências com vidro, considerando que a fratura ocorria em um material frágil ideal com uma trinca de comprimento $2 a$ no interior de uma chapa conforme Figura 4.1.

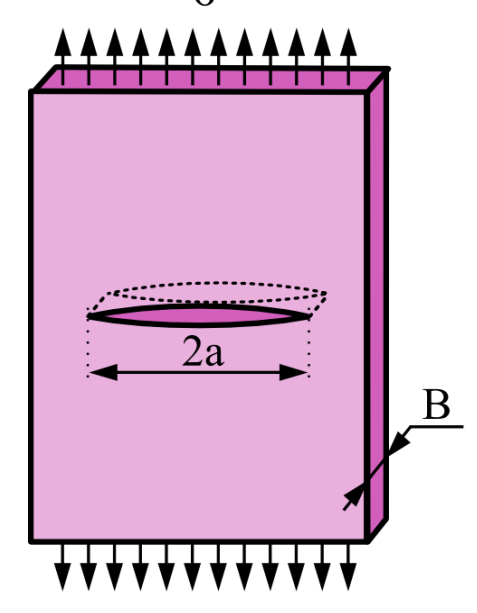

$\sigma$

Figura 4.1: Critério de Griffith.

Segundo Griffith, em materiais idealmente frágeis, a trinca se propaga de forma instável se a energia de deformação liberada quando a trinca avança a um comprimento infinitesimal é maior que a energia requerida para formar uma nova superfície de trinca.

Considerando a chapa mostrada na Figura 4.1, o balanço energético de Griffith para um incremento de área de trinca $d A$, sob condições de equilíbrio é dado por

$$
\frac{d E_{T}}{d A}=\frac{d \Pi}{d A}+\frac{d W_{S}}{d A}=0
$$

onde $E_{T}$ é a energia total do sistema, $\Pi$ é a energia potencial total de deformação na chapa e $W_{S}$ é a energia de formação das superfícies da trinca.

Griffith deduziu a partir das análises de Inglis que:

$$
\Pi=\Pi_{0}-\frac{\pi \sigma^{2} a^{2} B}{E}
$$

sendo $\Pi_{0}$ a energia potencial total de uma chapa sem trinca e B a espessura da chapa. 
Sendo $W_{S}$ o produto da nova superfície da área de trinca e a energia elástica da superfície do material, $\gamma_{S}$, tem-se que:

$$
W_{S}=2\left(2 a B \gamma_{S}\right)
$$

Substituindo as eqs. (4.2) e (4.3) em (4.1), obtém-se a tensão de fratura:

$$
\sigma_{f}=\left(\frac{2 E \gamma_{S}}{\pi a}\right)^{\frac{1}{2}}
$$

Esta equação é válida apenas para materiais frágeis. Ela relaciona a dimensão da imperfeição (2a) à resistência à tração do material, prevendo que imperfeições pequenas são menos prejudiciais que imperfeições grandes.

\subsection{Taxa de Alívio de Energia}

Em 1957, Irwin postulou uma teoria modificada à teoria de Griffith, ampliando o estudo da propagação da trinca.

Irwin definiu a "taxa de liberação de energia $(G)$ ", que corresponde à taxa de alívio da energia potencial armazenada no sistema por unidade de área da trinca:

$$
G=-\frac{d \Pi}{d A}
$$

Comparando-se o $G$ de um corpo fraturado à energia de fraturamento do material $\left(G_{C}\right)$, pode-se determinar se uma trinca irá ou não se propagar sob qualquer condição de carregamento. 


\subsection{Modos de Deformação}

O campo de deformação em torno de uma trinca num sólido qualquer, sob a ação de um carregamento, pode ser decomposto em três componentes ou modos de deformação (BROEK, 1986). Conforme a Figura 4.2, esses modos são descritos como:

- $\quad$ Modo I ou Modo de Abertura: as faces da trinca separam-se simetricamente com relação aos planos xy e xz.

- $\quad$ Modo II ou Modo de Cisalhamento Plano: as faces da trinca apresentam anti-simetria com relação ao plano xz e simetria com relação ao plano xy após a ocorrência da deformação. As faces da trinca separam-se em direções opostas, mas sob o mesmo plano.

- Modo III ou Modo de Cisalhamento Antiplano: as faces da trinca separam-se de forma anti-simétrica com relação aos planos formados pelos eixos xy e xz.

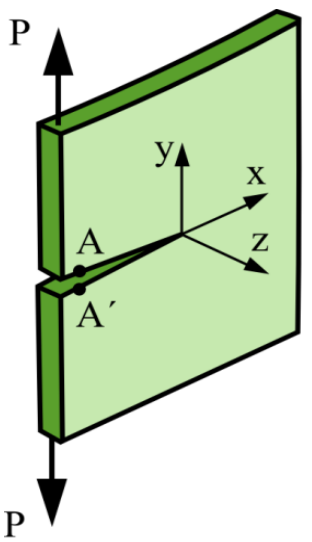

Modo I

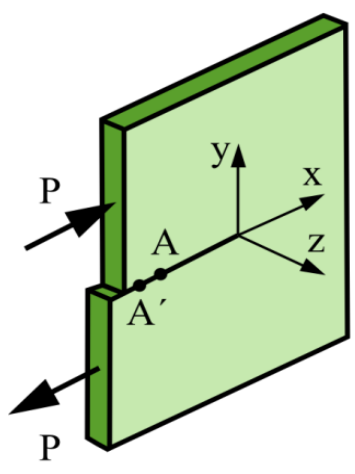

Modo II

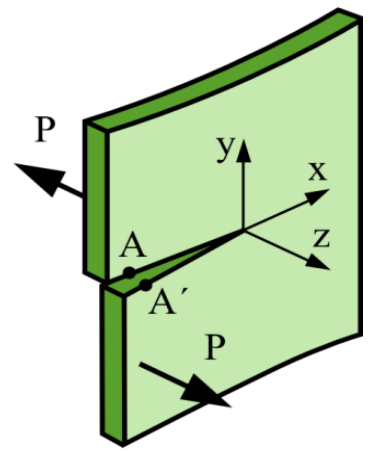

Modo III

Figura 4.2: Modos de Deformação. 


\subsection{Fator de Intensidade de Tensão}

O processo do balanço energético, usado na determinação da propagação das trincas, envolve uma árdua tarefa. Além disso, o termo $G$, referente à energia fornecida para o crescimento das trincas, reflete o estado de energia global da estrutura. Sendo assim, a necessidade de avaliação do comportamento isolado das trincas, torna esse processo custoso e ineficaz.

Irwin (1957) propôs que o balanço energético pode ser obtido utilizando um parâmetro conhecido por Fator de Intensidade de Tensão (FIT ou $K$ ). O $K$ fornece o campo de tensões nas regiões próximas à ponta da trinca, permitindo avaliar a evolução de seu comportamento.

Considere uma chapa de dimensões infinitas com uma trinca de tamanho $2 a$, solicitada biaxialmente por tensões remotas, $\sigma$. A distribuição de tensões à frente da ponta da trinca (Figura 4.3) é dada por:

$$
\sigma_{i j}(r, \theta)=\frac{K}{\sqrt{2 \pi r}} f_{i j}(r, \theta)
$$

onde $K$ é o Fator de Intensidade de Tensão, $r$ é a distância do ponto considerado à ponta da trinca, $\theta$ é o ângulo de orientação do ponto onde as tensões são calculadas e $f_{i j}(r, \theta)$ são funções trigonométricas conhecidas.

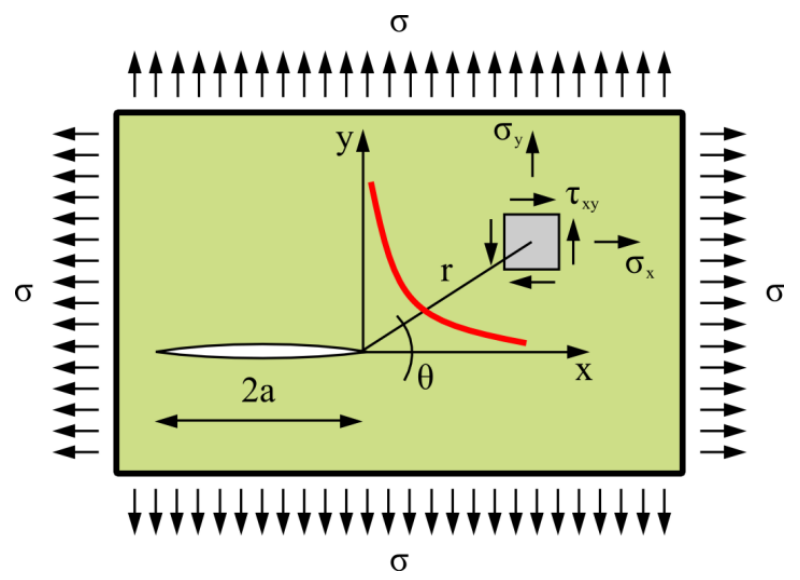

Figura 4.3: Tensões na ponta de uma trinca. 
O valor do Fator de Intensidade de Tensão, para diversos problemas, é encontrado em "handbooks", dentre os quais pode-se citar: Sih (1973), Tada et al. (2000) e Broek (1986).

O parâmetro $K$ é usualmente calculado pela seguinte expressão:

$$
K=\sigma \sqrt{\pi a} \beta
$$

onde $\sigma$ é a tensão aplicada na peça, $a$ é a metade do tamanho da trinca e $\beta$ é um parâmetro que depende das condições de carregamento, da geometria do corpo e do tamanho da trinca.

Sob regime elástico linear, o Fator de Intensidade de Tensão, $K$, relaciona-se com a taxa de liberação de energia, $G$, de um material conforme a eq. (4.8):

$$
G=\frac{K^{2}}{E^{\prime}}
$$

onde $E^{\prime}=E /\left(1-v^{2}\right)$ em deformação plana e $E^{\prime}=E$ em tensão plana. $E$ é o módulo de elasticidade e $v$ é o coeficiente de Poisson.

O valor crítico do Fator de Intensidade de Tensão, $K_{C}$, recebe o nome de Tenacidade à Fratura e é uma propriedade do material. Ele exprime a capacidade do material de resistir àfratura na presença de trincas.

Os valores de $K_{C}$ podem ser determinados por meio de ensaios medindo a tensão de fratura para uma dada estrutura com uma trinca de tamanho conhecido. Vários manuais foram escritos fornecendo relações entre os valores de $K_{C}$ para diversas estruturas com diferentes tamanhos de trincas, orientações, formas e carregamentos.

\subsection{Relação Campo de Tensão e Fator de Intensidade de Tensão}

As expressões do campo de tensões próximas à ponta da trinca, de acordo com Westergaard (1939), para os Modos I e II de deformação, são apresentadas a seguir: 
- Modo I:

$$
\begin{aligned}
& \sigma_{x x}=\frac{K_{I}}{\sqrt{2 \pi r}} \cos \frac{\theta}{2}\left[1-\operatorname{sen} \frac{\theta}{2} \operatorname{sen} \frac{3 \theta}{2}\right] . \\
& \sigma_{y y}=\frac{K_{I}}{\sqrt{2 \pi r}} \cos \frac{\theta}{2}\left[1+\operatorname{sen} \frac{\theta}{2} \operatorname{sen} \frac{3 \theta}{2}\right] . \\
& \tau_{x y}=\frac{K_{I}}{\sqrt{2 \pi r}} \operatorname{sen} \frac{\theta}{2} \cos \frac{\theta}{2} \cos \frac{3 \theta}{2} .
\end{aligned}
$$

- Modo II:

$$
\begin{aligned}
& \sigma_{x x}=-\frac{K_{I I}}{\sqrt{2 \pi r}} \operatorname{sen} \frac{\theta}{2}\left[2+\cos \frac{\theta}{2} \cos \frac{3 \theta}{2}\right] . \\
& \sigma_{y y}=\frac{K_{I I}}{\sqrt{2 \pi r}} \cos \frac{\theta}{2}\left[\operatorname{sen} \frac{\theta}{2} \cos \frac{\theta}{2} \cos \frac{3 \theta}{2}\right] . \\
& \tau_{x y}=\frac{K_{I I}}{\sqrt{2 \pi r}} \cos \frac{\theta}{2}\left[1-\operatorname{sen} \frac{\theta}{2} \operatorname{sen} \frac{3 \theta}{2}\right] .
\end{aligned}
$$

As variáveis $r$ e $\theta$ podem ser facilmente localizadas na Figura 4.3.

Para problemas do Modo Misto, envolvendo os Modos I e II, as expressões do campo de tensões próximas à ponta da trinca são dadas por:

$$
\begin{aligned}
& \sigma_{x x}=\frac{K_{I}}{\sqrt{2 \pi r}} \cos \frac{\theta}{2}\left[1-\operatorname{sen} \frac{\theta}{2} \operatorname{sen} \frac{3 \theta}{2}\right] \\
& -\frac{K_{I I}}{\sqrt{2 \pi r}} \operatorname{sen} \frac{\theta}{2}\left[2+\cos \frac{\theta}{2} \cos \frac{3 \theta}{2}\right] . \\
& \sigma_{y y}=\frac{K_{I}}{\sqrt{2 \pi r}} \cos \frac{\theta}{2}\left[1+\operatorname{sen} \frac{\theta}{2} \operatorname{sen} \frac{3 \theta}{2}\right] \\
& +\frac{K_{I I}}{\sqrt{2 \pi r}} \cos \frac{\theta}{2}\left[\operatorname{sen} \frac{\theta}{2} \cos \frac{\theta}{2} \cos \frac{3 \theta}{2}\right] .
\end{aligned}
$$




$$
\begin{aligned}
& \tau_{x y}=\frac{K_{I}}{\sqrt{2 \pi r}} \operatorname{sen} \frac{\theta}{2} \cos \frac{\theta}{2} \cos \frac{3 \theta}{2} \\
& +\frac{K_{I I}}{\sqrt{2 \pi r}} \cos \frac{\theta}{2}\left[1-\operatorname{sen} \frac{\theta}{2} \operatorname{sen} \frac{3 \theta}{2}\right]
\end{aligned}
$$

Verifica-se que as tensões apresentam uma singularidade devido à formulação em relação à distância $r$ da ponta da trinca. Quando $r$ tende a zero o valor da tensão tende ao infinito, mostrando o comportamento singular da expressão que rege o problema. Esta singularidade acontece devido à presença da trinca na peça. No entanto, a tensão teoricamente infinita só ocorre numa área infinitesimal, pois esta se reduz a uma distância próxima da ponta da trinca. 


\section{MÉTODO DOS ELEMENTOS DE CONTORNO}

Nas últimas décadas, o avanço da tecnologia computacional permitiu o desenvolvimento de uma grande variedade de ferramentas numéricas para análise de problemas de engenharia. Dentre elas destaca-se o Método dos Elementos de Contorno.

O Método dos Elementos de Contorno (MEC) é uma ferramenta numérica que envolve a resolução de equações integrais de contorno que governam um problema, fazendose a discretização apenas do contorno deste problema. Essa discretização corresponde a uma aproximação da geometria do contorno em elementos como mostrada na Figura 5.1.

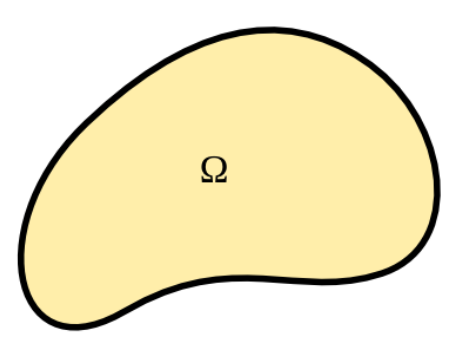

(a)

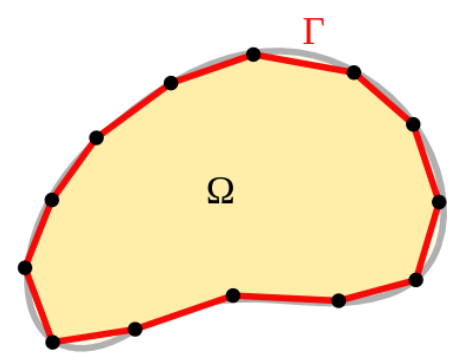

(b)

Figura 5.1: (a) Modelo estrutural; (b) Discretização com elementos de contorno.

A análise de problemas pelo MEC consiste basicamente em determinar os resultados no contorno e, em seguida, obter os resultados em qualquer ponto no domínio.

Apresenta-se, neste capítulo, uma revisão das principais características da formulação convencional do MEC para análise de problemas da elastostática.

\subsection{Formulação Direta}

Em geral, a formulação do MEC, para problemas da elastostática, pode ser feita de três formas distintas: pelo método direto, indireto e semi-indireto. $\mathrm{O}$ método direto utiliza 
parâmetros com significado físico, como deslocamentos e forças, enquanto os outros apresentam as formulações a partir de funções de densidade fictícias ou funções de tensões (BECKER, 1992).

A formulação direta ou convencional do MEC, para problemas da elastostática, baseia-se numa relação conhecida como Identidade de Somigliana, que é uma equação integral que envolve as Soluções Fundamentais. Esta formulação é descrita a seguir.

\subsubsection{Solução Fundamental}

A solução fundamental considerada neste trabalho foi desenvolvida por Kelvin e é definida como a resposta de um corpo elástico e de domínio infinito submetido à ação de uma carga unitária e concentrada aplicada num ponto Q, chamado de ponto fonte (Figura 5.2).

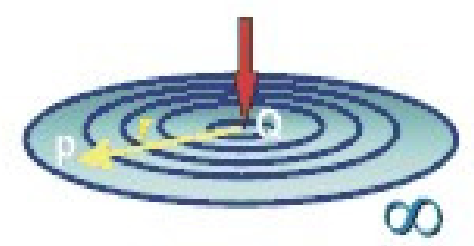

Figura 5.2: Solução Fundamental (PEREIRA, 2004).

A solução fundamental de Kelvin pode ser encontrada em Brebbia (1989) e Gaul (2003). As expressões para a solução fundamental de deslocamentos $u_{l k}{ }^{*}$ e forças de superfície $p_{l k}^{*}$ para o caso bidimensional são dadas por:

$$
\begin{aligned}
& u_{l k}^{*}=\frac{1}{8 \pi \mu(1-v)}\left[(3-4 v) \ln \left(\frac{1}{r}\right) \delta_{l k}+r_{,} r_{, k}\right]_{\mathrm{e}} \\
& p_{l k}^{*}=-\frac{1}{4 \pi(1-v) r}\left\{\frac{\partial r}{\partial n}\left[(1-2 v) \delta_{l k}+2 r_{,_{l}} r_{, k}\right]+(1-2 v)\left(n_{l} r_{,_{k}}-n_{k} r_{l}\right)\right\},
\end{aligned}
$$


onde $\mu$ é o módulo de elasticidade transversal do material, $v$ é o coeficiente de Poisson, $r$ é a distância entre o ponto fonte e o ponto campo (onde os valores de $u_{l k}{ }^{*} \mathrm{e} p_{l k}^{*}$ são observados) e n representa o vetor normal no ponto onde a força de superfície é avaliada.

\subsubsection{Equação Integral de Contorno}

Para o estudo do MEC é necessário conhecer as equações integrais de contorno, as quais relacionam os deslocamentos de um ponto qualquer do domínio com os deslocamentos e esforços no contorno de um corpo por meio de integrais envolvendo as soluções fundamentais. Neste trabalho, essas equações são obtidas por meio da técnica dos resíduos ponderados, utilizando a solução fundamental como a função ponderadora.

\subsubsection{Equação Integral para pontos do domínio}

Seja um sólido homogêneo definido por um domínio $\Omega$ e delimitado por um contorno $\Gamma$, onde $\Gamma=\Gamma_{1}+\Gamma_{2}$, sendo conhecido em cada ponto do contorno o deslocamento ou a força de superfície atuante (Figura 5.3). As condições de contorno para o problema são dadas por:

- Condições de contorno essenciais ou de Dirichilet:

$$
u_{k}=\bar{u}_{k} \text { em } \Gamma_{1}
$$

- Condições de contorno naturais ou de Neumann:

$$
p_{k}=\bar{p}_{k} \text { em } \Gamma_{2} \text {. }
$$




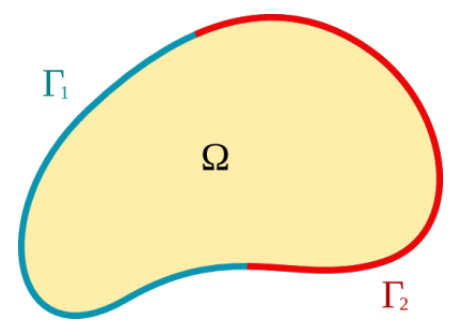

Figura 5.3: Sólido homogêneo de domínio $\Omega$.

Considerando que este sólido satisfaça a equação de equilíbrio da Teoria da Elasticidade, a formulação convencional do MEC pode ser obtida por meio da técnica dos resíduos ponderados empregada sobre a equação de equilíbrio (eq. 3.5). A função ponderadora é a solução fundamental $u^{*}$.

$$
\int_{\Omega}\left(\sigma_{k j, j}+b_{k}\right) u_{k}^{*} d \Omega=0
$$

Integrando-se duas vezes por partes e aplicando o Teorema do Divergente é possível levar a integral de domínio para o contorno. Aplicando as relações da teoria da Elasticidade, apresentadas no capítulo 3, obtém-se a equação denominada de Identidade de Somigliana, dada pela seguinte expressão:

$$
u_{l}^{i}=\int_{\Gamma} p_{k} u_{l k}^{*} d \Gamma-\int_{\Gamma} u_{k} p_{l k}^{*} d \Gamma+\int_{\Omega} b_{k} u_{l k}^{*} d \Omega .
$$

A Identidade de Somigliana permite obter os valores dos deslocamentos para qualquer ponto interno do domínio, considerando que os deslocamentos e forças de superfície no contorno sejam conhecidos. Embora as forças de volume sejam definidas em uma integral de domínio, essas forças são conhecidas e não adicionam nenhuma incógnita ao sistema de equações.

Obtida a Identidade de Somigliana para deslocamentos em pontos internos, é possível determiná-la para deformação e tensão, utilizando as equações de compatibilidade e relações constitutivas, respectivamente, como indicado em Aliabadi (2002). 


\subsubsection{Equação Integral para pontos do contorno}

A partir da Identidade de Somigliana pode-se obter os deslocamentos de qualquer ponto do domínio. No entanto, é preciso ainda determinar os valores incógnitos dos deslocamentos e forças de superfície no contorno. Para isso, utiliza-se de um artifício que transforma, inicialmente, um ponto de contorno em um ponto de domínio, sobre o qual se pode aplicar a Identidade de Somigliana.

$\mathrm{O}$ artifício consiste em acrescentar um domínio complementar infinitesimal $\Omega_{\varepsilon}$ com centro no ponto fonte do contorno e de raio $\varepsilon$ (Figura 5.4). Dessa forma, o ponto do contorno se transforma, transitoriamente, num ponto de domínio, estabelecendo para ele a Identidade de Somigliana com o domínio e contorno acrescidos do domínio $\Omega_{\varepsilon}$. Feito isso, determina-se o limite das parcelas acrescidas anteriormente para $\varepsilon \rightarrow 0$ resultando na equação integral para pontos do contorno.

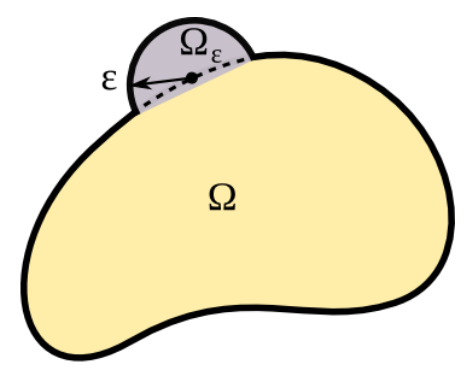

Figura 5.4: Domínio expandido.

Assim, a equação integral para pontos do contorno é expressa por:

$$
c_{l k}^{i} u_{k}^{i}=\int_{\Gamma} p_{k} u_{l k}^{*} d \Gamma-\int_{\Gamma} u_{k} p_{l k}^{*} d \Gamma+\int_{\Omega} b_{k} u_{l k}^{*} d \Omega
$$

onde o coeficiente $c^{i}$ depende da geometria do contorno na vizinhança do nó $i$.

O Método dos Elementos de Contorno é uma ferramenta numérica usada para resolver a equação acima de forma aproximada. 


\subsubsection{Sistema de Equações}

As equações integrais de contorno servem de base para o MEC e são utilizadas no método fazendo-se a discretização do sólido em elementos do contorno, permitindo transformar essas equações integrais em equações algébricas, a fim de que possam ser resolvidas numericamente.

Os deslocamentos e forças de superfície são representados em termos de uma série de valores nodais, podendo ser estendidos para todo o contorno utilizando-se funções de interpolação sobre cada elemento do contorno. Assim, os deslocamentos e forças de superfície ficam determinados por:

$$
\begin{aligned}
& \mathbf{u}=\boldsymbol{\varphi}_{j} \mathbf{u}^{j} \mathrm{e} \\
& \mathbf{p}=\boldsymbol{\varphi}_{j} \mathbf{p}^{j},
\end{aligned}
$$

onde $\boldsymbol{\varphi}_{j}$ são as funções de interpolação e $\mathbf{u}^{j}$ e $\mathbf{p}^{j}$ são os valores dos deslocamentos e forças de superfície nos nós dos elementos.

Desconsiderando as forças de volume na equação integral de contorno (eq. 5.7) e aplicando as aproximações apresentadas sobre esta equação é determinada a equação:

$$
\mathbf{c}^{i} \mathbf{u}^{i}+\sum_{j=1}^{N E}\left\{\int_{\Gamma_{j}} \mathbf{p}^{*} \boldsymbol{\varphi} d \Gamma\right\} \mathbf{u}^{j}=\sum_{j=1}^{N E}\left\{\int_{\Gamma_{j}} \mathbf{u}^{*} \boldsymbol{\varphi} d \Gamma \mathbf{p}^{j}\right.
$$

sendo $N E$ o número de elementos de contorno.

A aplicação da (eq. 5.10) para todos os nós do contorno, resulta no seguinte sistema de equações:

$$
\mathbf{H u}=\mathbf{G p},
$$

onde $\mathbf{H e}$ G são matrizes densas e não-simétricas, u e $\mathbf{p}$ os vetores de deslocamentos e forças de superfície, respectivamente. 
Introduzindo as condições de contorno no sistema de eq. (5.11) e passando para o lado esquerdo as incógnitas e para o lado direito os valores conhecidos, chega-se ao seguinte sistema de equações lineares

$$
\mathbf{A x}=\mathbf{F},
$$

onde a matriz A é formada por elementos das matrizes $\mathbf{H e} \mathbf{G}, \mathbf{x}$ é o vetor de deslocamentos e forças de superfície desconhecidos e Fé o vetor de deslocamentos e forças de superfície conhecidos.

Resolvendo o sistema da eq. (5.12) obtêm-se os deslocamentos e forças de superfície para todos os nós do contorno. Os resultados de deslocamentos e forças de superfície podem ser estendidos para todo o contorno usando as funções de interpolação dadas pelas eq. (5.8) e (5.9).

\subsubsection{Resultados em pontos internos}

Depois de calculados todos os valores de deslocamentos do contorno, podem-se calcular os deslocamentos em pontos internos do domínio $\Omega$ utilizando-se a Identidade de Somigliana (eq 5.6). De forma similar, os resultados do tensor das tensões podem ser obtidos em pontos internos, aplicando-se as equações constitutivas e de compatibilidade, sendo dado por:

$$
\sigma_{i j}=\int_{\Gamma} D_{k i j} p_{k} d \Gamma-\int_{\Gamma} S_{k i j} u_{k} d \Gamma
$$

onde $D_{k i j}$ e $S_{k i j}$ são dados por:

$$
\begin{aligned}
& D_{k i j}=\frac{1}{4 \pi(1-v) r}\left\{(1-2 v)\left(\delta_{k i} r,{ }_{j}+\delta_{k j} r_{{ }_{i}}-\delta_{i j} r_{{ }_{k}}\right)+2 r_{,} r,_{j} r_{k}\right\}_{\mathrm{e}} \\
& S_{k i j}=\frac{\mu}{2 \pi(1-v) r^{2}}\left\{2 \frac{\partial r}{\partial n}\left[(1-2 v) \delta_{i j} r_{k}+v\left(\delta_{i k} r,_{j}+\delta_{j k} r_{i}\right)-4 r,_{i} r_{j}{ }_{j} r_{k}\right]+\right. \\
& \left.+2 v\left(n_{i} r,_{j} r,_{k}+n_{j} r_{i} r_{{ }_{k}}\right)+(1-2 v)\left(2 n_{k} r_{{ }_{i}} r_{j}+n_{j} \delta_{i k}+n_{i} \delta_{j k}\right)-(1-4 v) n_{k} \delta_{i j}\right\} .
\end{aligned}
$$




\subsection{Técnica de Integração para Resolução das Integrais Quase Singulares}

A modelagem de problemas bidimensionais de fratura, aliada à formulação integral do Método dos Elementos de Contorno (MEC), apresenta grandes vantagens na análise de problemas da Mecânica da Fratura Computacional.

Entretanto, na modelagem da trinca discreta, a separação das faces da trinca por uma abertura $(\delta)$ muito pequena em relação ao comprimento (a) dessa trinca (Figura 5.5) leva ao surgimento de integrais quase singulares, causando erros numéricos significativos e, conseqüentemente, um efeito prejudicial sobre a solução.

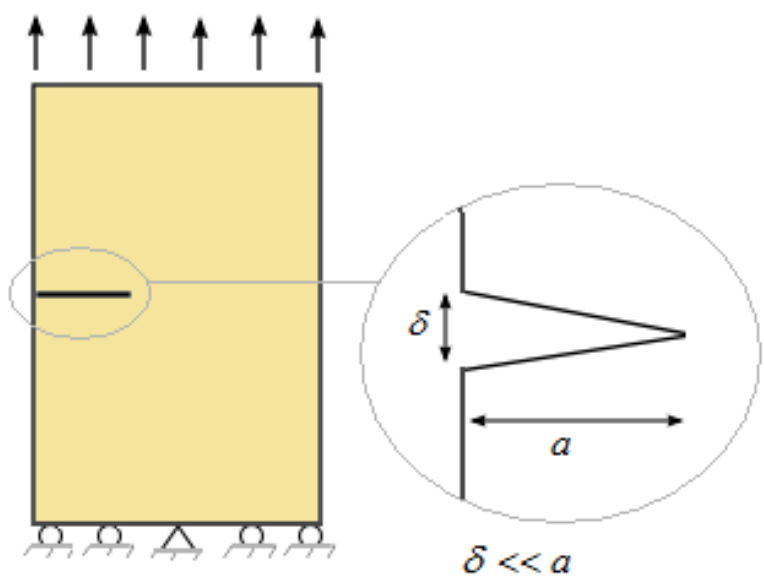

Figura 5.5: Ilustração da trinca discreta.

Nesse contexto, foi utilizada uma técnica de integração desenvolvida por Dumont e Noronha (1998) para resolução dessas integrais. Essa técnica de integração é usada na resolução de integrais singulares, quase singulares e regulares.

Para analisar as integrais singulares e quase singulares é necessário, inicialmente, conhecer qual ponto faz o integrando tender ao infinito. Este ponto é denominado de Pólo de Singularidade e sua influência no integrando pode ser observada quando se analisa a distância desse ponto ao intervalo de integração.

Um esquema para classificação das integrais e de seus pólos está apresentado em Noronha (1998). Este considera que o intervalo de integração está normalizado e é 
representado por meio da coordenada $\xi$ variando de 0 a 1 (Figura 5.6). Este esquema baseiase na posição relativa entre o pólo e o intervalo de integração, podendo ocorrer três casos.

Quando o pólo situa-se sobre o intervalo de integração em uma posição $\xi_{0}$ (ponto A da Figura 5.6) pode ser classificado como pólo de singularidade, já que resultante é singular (ou imprópria, dependendo da função de singularidade). Quando o pólo situa-se sobre a extensão natural do intervalo de integração em uma posição arbitrária (real) $\xi_{0}$ (ponto B da Figura 5.6), o pólo é classificado como sendo de quase-singularidade real e, quando o pólo situa-se fora do intervalo de integração e próximo a este, é classificado como pólo de quasesingularidade complexo (ponto $\mathrm{C}$ da Figura 5.6) sendo expresso por $\xi_{0}=a \pm b i$.

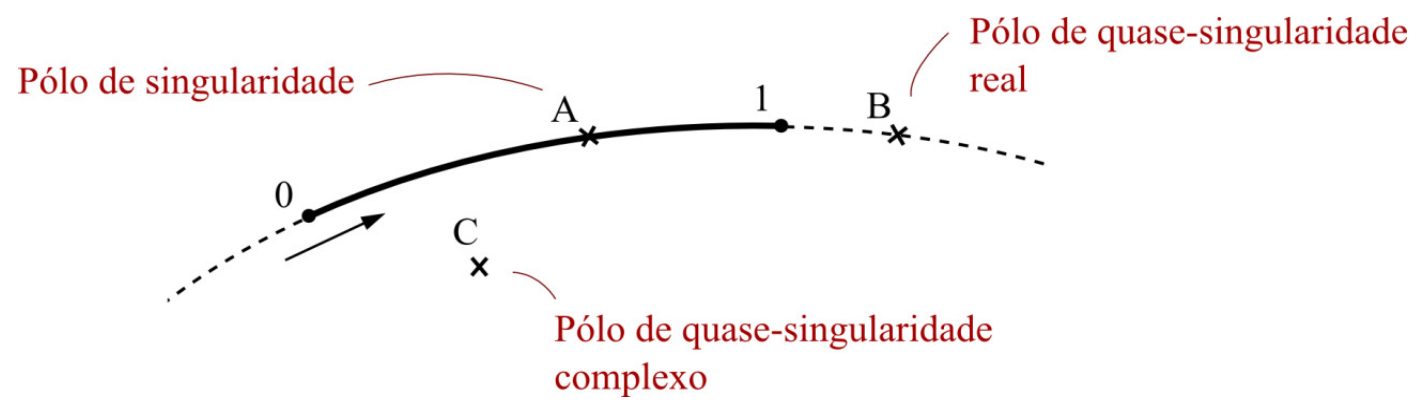

Figura 5.6 - Classificação dos pólos de singularidade para o caso 2d.

O problema da quase singularidade, presente na análise de trincas discretas, pode ser observado quando o ponto P está situado sobre uma das faces da trinca e a integração é realizada sobre a face oposta (Figura 5.7). Devido ao uso das soluções de Kelvin, a distância $r$ entre o ponto $\mathrm{P}$ e o intervalo de integração, é a responsável pela quase singularidade (complexa) das integrais do MEC.

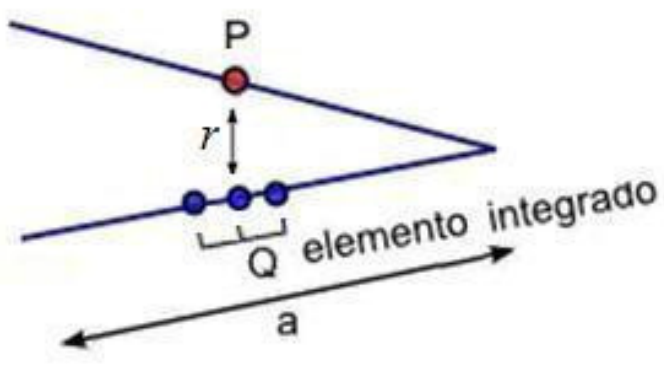

Figura 5.7: Exemplo de uma situação de quase singularidade. 
A quase singularidade leva ao mau condicionamento matricial do MEC, onde qualquer pequena perturbação no sistema de equações pode interferir na estabilidade do problema estudado. Para tratar as integrais quase singulares é utilizada uma técnica de integração desenvolvida por Dumont e Noronha (1998) que resolve de forma precisa essas integrais mantendo a estabilidade numérica do problema.

Essa técnica baseia-se numa função $w=w(\xi)$, que representa a distância entre o pólo e o intervalo de integração no sistema de coordenadas $\xi$. No sistema $(x, y)$, a distância entre o pólo e o intervalo de integração pode ser expressa por:

$$
r(\xi)=\sqrt{\left(x(\xi)-x_{0}\right)^{2}+\left(y(\xi)-y_{0}\right)^{2}}=w(\xi) \bar{r}(\xi),
$$

onde $w(\xi)$ representa a parcela singular presente em $r(\xi)$ e $\bar{r}(\xi)$ a parcela regular.

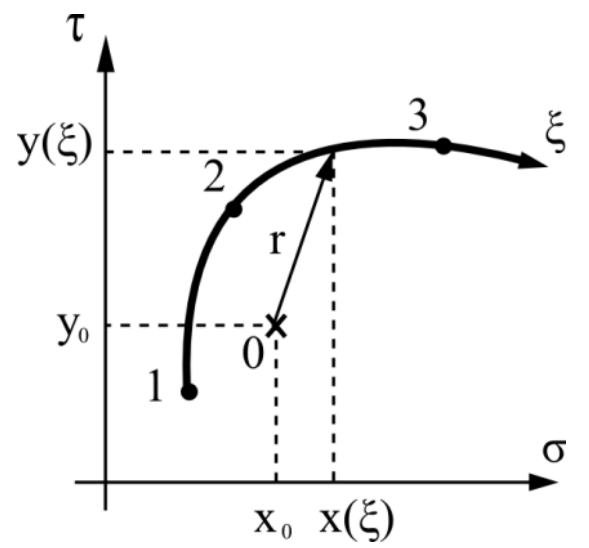

Figura 5.8: Representação de um elemento quadrático para problemas bidimensionais no MEC.

Considere uma integral onde $g(\xi)$ representa a parte regular do integrando e $\omega(\xi)$ sua parte singular. Na resolução das integrais quase singulares, a técnica de integração é expressa por:

$$
\int_{0}^{1} \omega(\xi) g(\xi) d \xi \approx \sum_{i=1}^{n} g\left(\xi_{i}\right) h_{i}+\sum_{j=1}^{2 m} R_{j} C_{j}
$$

onde $C_{j}$ são pesos específicos de integração associados a $\omega(\xi)$ e $R_{j}$ depende da função $g(\xi)$ e de suas derivadas de ordem $m-1$ avaliadas em $\xi_{0}=a \pm b i$.

$\mathrm{O}$ segundo termo do lado direito da eq. (5.17) tem a finalidade de corrigir ou simplesmente melhorar o resultado final da integração. $O$ parâmetro $m$ pode ser relacionado 
ao grau de singularidade da parcela $\varpi(\xi)$. Observa-se então que esta técnica apresenta grande vantagem em oferecer ganho de precisão para funções de singularidades cada vez mais fortes, quando comparado à maioria das técnicas existentes.

Maiores detalhes sobre esta técnica encontram-se no trabalho de Dumont e Noronha (1998). 


\title{
6 CONSIDERAÇÕES SOBRE A IMPLEMENTAÇÃO COMPUTACIONAL
}

\begin{abstract}
Neste capítulo são abordados tópicos importantes sobre as implementações computacionais desenvolvidas neste trabalho. Dentre os assuntos apresentados têm-se as técnicas utilizadas para obtenção do Fator de Intensidade de Tensão e a técnica para estudo da direção da propagação da trinca.
\end{abstract}

6.1 Técnicas numéricas para obtenção do Fator de Intensidade de Tensão

A aplicação do Método dos Elementos de Contorno a problemas envolvendo Mecânica da Fratura permite avaliar os Fatores de Intensidade de Tensão relacionando as soluções dos elementos de contorno com as expressões teóricas de deslocamentos e tensões próximas à ponta da trinca.

Nesse trabalho, duas técnicas são utilizadas para a obtenção do Fator de Intensidade de Tensão: a técnica de correlação dos deslocamentos a qual foi utilizada nos trabalhos de Bittencourt et. al. (2003) e a técnica baseada no estado de tensões à frente da ponta da trinca proposta por Maciel (2003) e inspirada no trabalho de Paris \& Cañas (1997). 


\subsubsection{Técnica de Correlação dos Deslocamentos}

Na técnica de correlação dos deslocamentos, os Fatores de Intensidade de Tensão são calculados relacionando as soluções obtidas pelo Método dos Elementos de Contorno com expressões teóricas dos deslocamentos próximos à ponta da trinca.

Por meio das funções de tensão de Westergaard (1939) podem-se obter as equações que descrevem o campo de deslocamentos na região próxima à ponta da trinca, dadas por:

$$
\begin{aligned}
& u_{1}=\frac{1}{4 \mu} \sqrt{\frac{2 r}{\pi}}\left\{K_{I}\left[(2 \kappa-1) \cos \frac{\theta}{2}-\cos \frac{3 \theta}{2}\right]\right. \\
& \left.+K_{I I}\left[(2 \kappa+3) \operatorname{sen} \frac{\theta}{2}+\operatorname{sen} \frac{3 \theta}{2}\right]\right\} \\
& u_{2}=\frac{1}{4 \mu} \sqrt{\frac{2 r}{\pi}}\left\{K_{I}\left[(2 \kappa-1) \operatorname{sen} \frac{\theta}{2}-\operatorname{sen} \frac{3 \theta}{2}\right]\right. \\
& \left.+K_{I I}\left[(2 \kappa+3) \cos \frac{\theta}{2}+\cos \frac{3 \theta}{2}\right]\right\},
\end{aligned}
$$

sendo:

$\mu$ : Módulo de Elasticidade Transversal;

$$
\kappa=\left\{\begin{array}{l}
(3-v) /(1+v), \text { EPT } \\
(3-4 v), \text { EPD }
\end{array}\right.
$$

$\theta$ : Ângulo de inclinação do ponto considerado à ponta da trinca;

$r$ : Distância do ponto considerado à ponta da trinca.

Para obter os Fatores de Intensidade de Tensão, as eq. (6.1) e (6.2) são avaliadas para ângulos iguais a $\pi \mathrm{e}-\pi$, ou seja, nas faces da trinca, como ilustrado na Figura 6.1. 


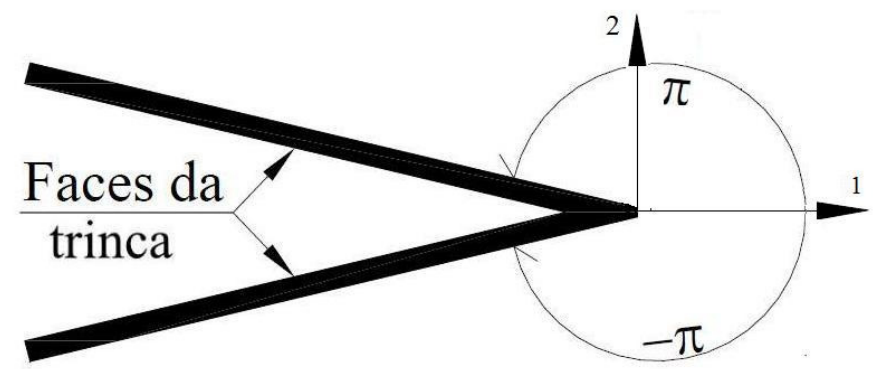

Figura 6.1: Avaliação das equações de deslocamentos nas faces da trinca.

As expressões obtidas para os ângulos iguais a $\pi \mathrm{e}-\pi$ devem ser subtraídas de forma a obter equações que determinem os Fatores de Intensidade de Tensão em função da diferença de deslocamentos das faces da trinca. Sendo assim, são obtidas as seguintes equações:

$$
\begin{aligned}
& u_{1}(\theta=\pi)-u_{1}(\theta=-\pi)=\frac{\kappa+1}{\mu} K_{I I} \sqrt{\frac{r}{2 \pi}} . \\
& u_{2}(\theta=\pi)-u_{2}(\theta=-\pi)=\frac{\kappa+1}{\mu} K_{I} \sqrt{\frac{r}{2 \pi}} .
\end{aligned}
$$

Para a implementação computacional dessa técnica foram considerados os deslocamentos dos dois pares de pontos fontes pertencentes aos dois elementos situados na extremidade da trinca (figura 6.2).

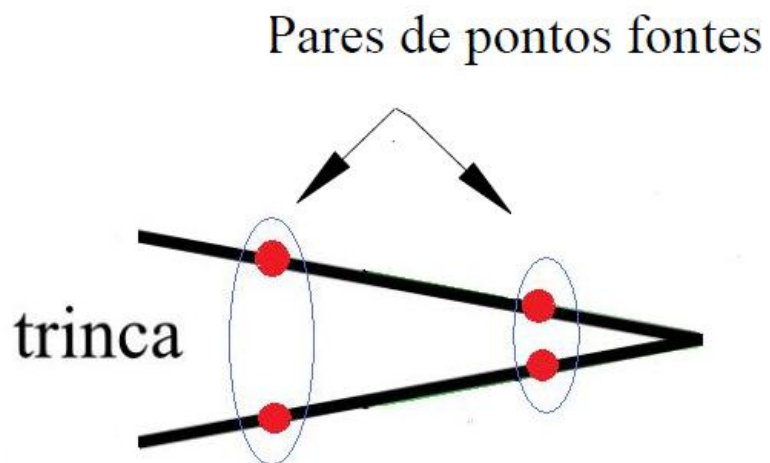

Figura 6.2: Localização dos pontos fontes usados na Técnica de Correlação dos Deslocamentos.

Os Fatores de Intensidade de Tensão são calculados, inicialmente, para o primeiro par de pontos fontes situado mais próximo da ponta da trinca. Em seguida repetem-se os 
cálculos para os pontos fontes localizados na extremidade do elemento mais distante da ponta da trinca.

O Fator de Intensidade de Tensão para a trinca é considerado como sendo a média aritmética dos valores determinados para os dois pares de pontos fontes situados na extremidade da trinca. O procedimento adotado fornece bons resultados, como será apresentado no capítulo 7.

\subsubsection{Técnica com base nas tensões}

Neste tópico é abordada a metodologia proposta por Maciel (2003) para o cálculo do Fator de Intensidade de Tensão. Essa técnica é uma padronização da técnica proposta por Paris \& Cañas (1997), os quais sugerem que os Fatores de Intensidade de Tensão podem ser determinados pela geração de curvas de tensão em função da distância à ponta da trinca para pontos situados à frente da ponta da trinca. Destaca-se ainda que os pontos considerados para esse estudo apresentem a mesma inclinação da trinca, ou seja, $\theta=0$.

As expressões que relacionam o campo de tensões e a distância referente à ponta da trinca são apresentadas nas eqs. (4.9) a (4.14) do capítulo 4. Quando as curvas de tensão são geradas, efetua-se a linearização das curvas, via operador logaritmo e em seguida, uma regressão linear obtendo-se então o Fator de Intensidade de Tensão.

Nesse contexto, Maciel (2003) apresentou uma metodologia na qual propõe a extração dos Fatores de Intensidade de Tensão por meio de três pontos internos localizados à frente da ponta da trinca usando o MEC. Os pontos considerados em suas análises estão situados a $\frac{a}{8}, \frac{a}{7} e \frac{a}{6}$, da ponta da trinca, onde $a$ é a metade do comprimento da trinca. Nesse trabalho, os pontos estão localizados a $\frac{a}{10}, \frac{a}{9} e \frac{a}{8}$ da ponta da trinca, pois nesses pontos a solução numérica aproxima-se da solução analítica (Figura 6.3). 


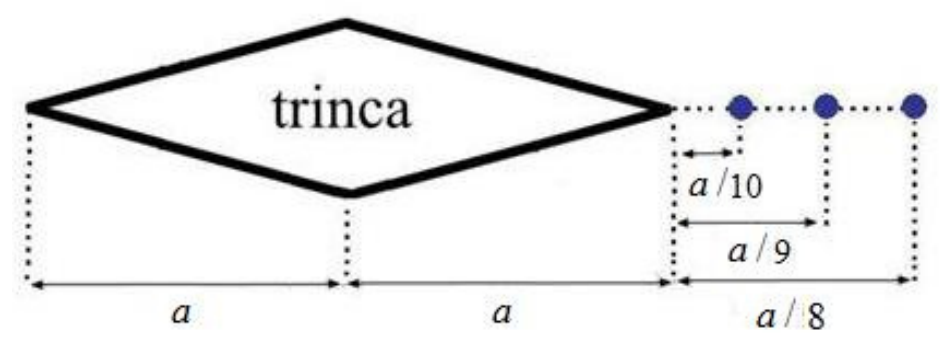

Figura 6.3: Localização dos pontos para obtenção do Fator de Intensidade de Tensão.

A necessidade de apenas três pontos internos, além da posição desses pontos à frente da trinca, torna o processo mais simples e rápido, permitindo alcançar rapidamente a convergência para os valores do FIT onde esses pontos se encontram.

Seguindo a metodologia proposta por Maciel (2003), os Fatores de Intensidade de Tensão são determinados em cada um dos três pontos selecionados por meio das eqs. (4.9) a (4.17). Em seguida, efetua-se a média aritmética dos valores obtidos nesses três pontos obtendo-se assim o FIT para a trinca.

Esse procedimento é semelhante ao usado na técnica de correlação dos deslocamentos. A diferença é que, nessa técnica, são utilizadas expressões do campo tensões e não deslocamentos. Além disso, os pontos estão situados à frente da trinca.

\subsection{Direção de Propagação da Trinca}

Nesta seção é apresentado o critério utilizado para avaliar a direção da propagação da trinca usando o MEC e a metodologia usada para estudo da propagação. Para simular a propagação é utilizado o critério da Máxima Tensão Circunferencial. 


\subsubsection{Critério da Máxima Tensão Circunferencial}

O critério da Máxima Tensão Circunferencial, proposto por Erdogan e Sih (1963), estabelece que a propagação da trinca ocorra num plano perpendicular à direção da máxima tensão circunferencial atuante na ponta da trinca.

A formulação utilizada para determinar o ângulo de propagação baseia-se nas expressões que relacionam o campo de tensão (eq. 4.15 a 4.17) na ponta da trinca aos Fatores de Intensidade de Tensão. Essas expressões são dadas a seguir em coordenadas polares (Figura 6.3):

$$
\begin{aligned}
& \sigma_{r r}=\frac{1}{\sqrt{2 \pi r}} \cos \frac{\theta}{2}\left\{K_{I}\left[1+\operatorname{sen}^{2}\left(\frac{\theta}{2}\right)\right]+\frac{3}{2} K_{I I} \operatorname{sen} \theta-2 K_{I I} \operatorname{tg}\left(\frac{\theta}{2}\right)\right\} \\
& \sigma_{\theta \theta}=\frac{1}{\sqrt{2 \pi r}} \cos \frac{\theta}{2}\left[K_{I} \cos ^{2}\left(\frac{\theta}{2}\right)-\frac{3}{2} K_{I I} \operatorname{sen} \theta\right] \\
& \tau_{r \theta}=\frac{1}{\sqrt{2 \pi r}} \cos \frac{\theta}{2}\left[K_{I} \operatorname{sen} \theta+K_{I I}(3 \cos \theta-1)\right],
\end{aligned}
$$

sendo:

$$
\begin{aligned}
& \sigma_{\theta \theta}: \text { Tensão Circunferencial; } \\
& \sigma_{r r}: \text { Tensão Radial; } \\
& \tau_{r \theta}: \text { Tensão Cisalhante. }
\end{aligned}
$$

Essas expressões são válidas tanto para estado plano de tensão como para estado plano de deformação. 


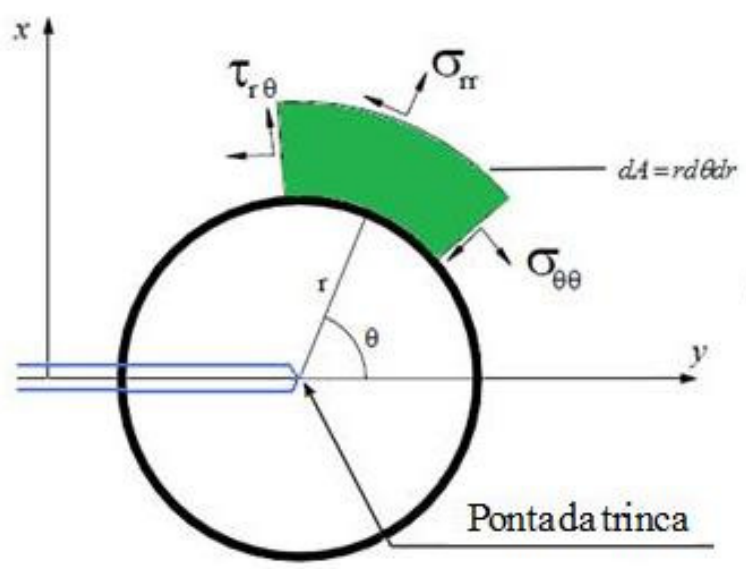

Figura 6.3: Tensões nas proximidades da ponta da trinca em coordenadas polares.

Para determinar o ângulo de propagação, $\sigma_{\theta \theta \text { maxx }}$ deve ser máxima e, portanto, $\tau_{r \theta}=0$. Por meio dessa condição é possível obter:

$$
K_{I} \operatorname{sen} \theta+K_{I I}(3 \cos \theta-1)=0 .
$$

Empregando relações trigonométricas pode-se reescrever a relação acima como:

$$
\theta=2 \operatorname{arctg}\left(\frac{1}{4} \frac{K_{I}}{K_{I I}} \pm \frac{1}{4} \sqrt{\left(\frac{K_{I}}{K_{I I}}\right)^{2}+8}\right)
$$

Por meio da resolução da eq. (6.9) são obtidos dois ângulos, sendo o ângulo considerado como o de propagação da trinca aquele que maximiza o valor da tensão circunferencial, eq. (6.6).

6.2.2 Metodologia para análise da direção de propagação da trinca

A simulação da propagação da trinca discreta é um processo iterativo e consiste nas seguintes etapas: 
- Análise, via MEC, da malha inicial contendo a trinca discreta;

- Cálculo dos Fatores de Intensidade de Tensão;

- Determinação da direção da extensão da trinca, com uma nova localização da ponta da mesma;

- Atualização da geometria da trinca com a inclusão da extensão da trinca;

A cada novo passo é realizada uma nova análise das tensões e dos deslocamentos pelo MEC e apenas a malha da trinca é atualizada.

A seguir, o processo de propagação da trinca é apresentado de forma mais detalhada.

Inicialmente são determinados as tensões e os deslocamentos da configuração inicial do problema via MEC e obtido os Fatores de Intensidade de Tensão pelo método de Extrapolação dos Deslocamentos . Em seguida, é determinado o ângulo de inicialização da propagação da trinca, determinado pelo critério da Máxima Tensão Circunferencial.

Estende-se à trinca um incremento na direção calculada, sendo o valor do incremento um percentual do tamanho da trinca inicial. Após a atualização da geometria da trinca, determinam-se as tensões e os deslocamentos para a nova configuração do problema, obtêm-se os novos Fatores de Intensidade de Tensão e determina-se a nova direção da propagação da trinca e assim sucessivamente.

O ângulo de propagação obtido inicialmente é comparado ao ângulo de propagação encontrado na etapa seguinte. Se a diferença entre eles estiver dentro de uma tolerância pré-estabelecida na análise, é acrescentado à trinca um incremento com comprimento igual ao do incremento inicial.

Caso contrário, o processo é repetido, realizando-se o procedimento a partir da etapa inicial. O novo incremento de trinca a ser considerado é a metade do incremento considerado na etapa inicial. 


\section{RESULTADOS NUMÉRICOS}

Neste capítulo são apresentados os resultados numéricos da determinação do Fator de Intensidade de Tensão utilizando a técnica de correlação dos deslocamentos e a técnica baseada no estado de tensões nas proximidades da ponta da trinca. Os problemas são analisados no Modo I e Modo Misto (Modos I e II) e comparados à solução analítica.

Além disso, são apresentados exemplos referentes à direção de propagação da trinca e comparadas à solução analítica e referências da literatura. A direção da propagação das trincas é analisada por meio do critério da Máxima Tensão Circunferencial.

\subsection{Determinação do Fator de Intensidade de Tensão}

Nesta seção são apresentados três exemplos numéricos para a determinação do Fator de Intensidade de Tensão. O primeiro exemplo tem a finalidade de mostrar, com mais detalhes, os procedimentos utilizados.

\subsubsection{Problema com trinca de borda horizontal}

O problema analisado trata-se de uma chapa retangular, com uma trinca de borda horizontal, submetida a uma tensão uniforme (Figura 7.1).

O problema apresenta as seguintes características:

Estado Plano de Tensão (EPT). 
Coeficiente de Poisson: $v=0.2$.

Módulo de Elasticidade: $E=3000 \mathrm{KN} / \mathrm{cm}^{2}$.

Dimensões: $W=10 \mathrm{~cm}, L_{1}=10 \mathrm{~cm}, L_{2}=10 \mathrm{~cm}, a=1 \mathrm{~cm}$.

Tensão aplicada: $\sigma=10 \mathrm{KN} / \mathrm{cm}^{2}$.

Abertura entre as faces da trinca: $\delta=210^{-3} a$.

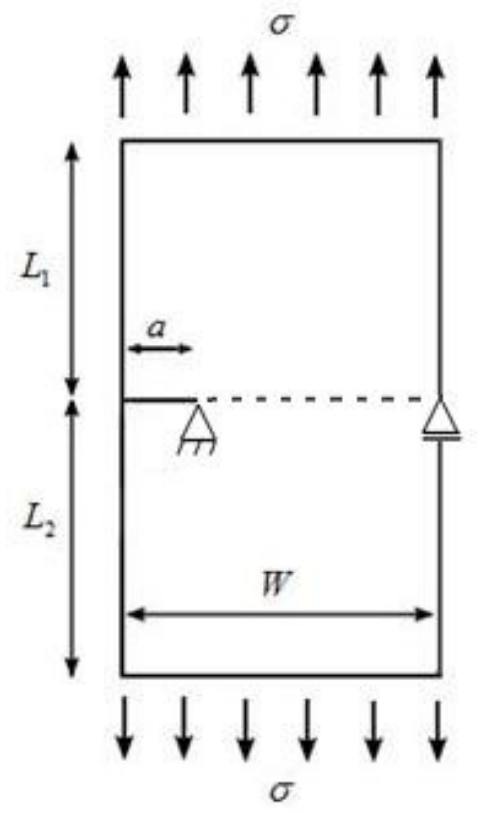

Figura 7.1: Chapa com trinca de borda horizontal.

O problema foi discretizado utilizando-se 41 elementos quadráticos, sendo 8 elementos quadráticos considerados para a discretização da trinca. A deformada para o problema é dada por (Figura 7.2): 


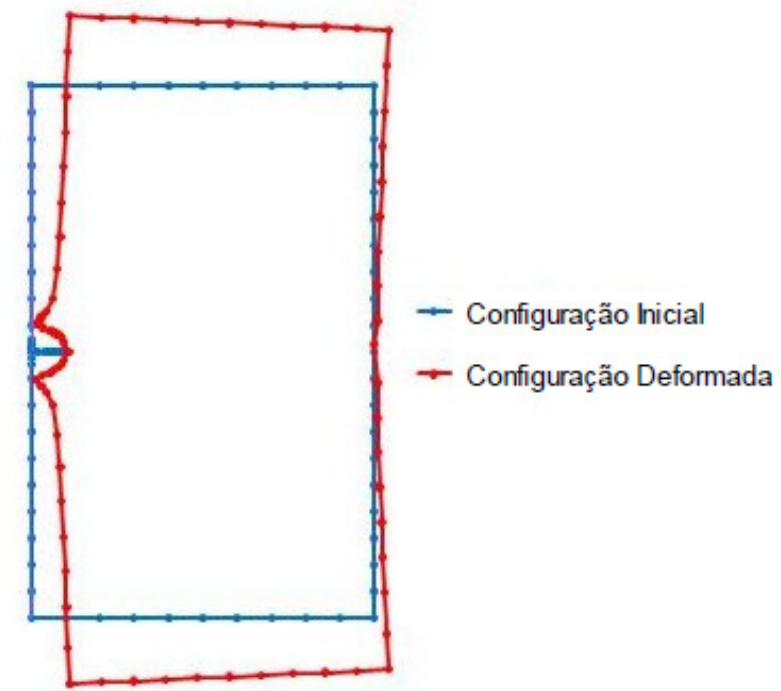

Figura 7.2: Configuração deformada da chapa com trinca de borda horizontal.

Na figura 7.3 é apresentada a abertura da trinca considerando a malha inicial e a malha deformada.

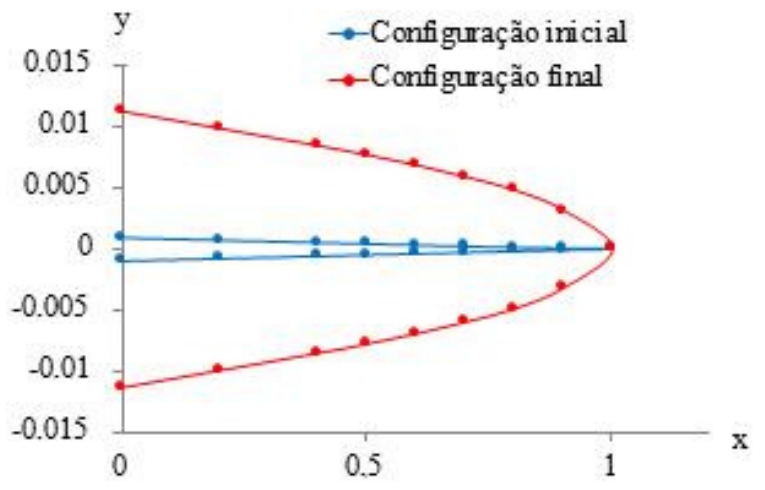

Figura 7.3: Abertura da trinca.

Para a configuração estudada, $K_{I}$ pôde ser analiticamente obtido pela equação (7.1), encontrada em Tada et al. (2000). De acordo com a referência, a precisão da fórmula para o cálculo de $K_{I}$ é de $1 \%$ para valores de $a / W<0,2$ e de $0,5 \%$ para $a / W \geq 0,2$. 


$$
K_{I}=\sigma \sqrt{\pi a}\left[\sqrt{\frac{2 W}{\pi a} \operatorname{tg}\left(\frac{\pi a}{2 W}\right)}\left(\frac{0.752+2.02\left(\frac{a}{W}\right)+0.37\left(1-\operatorname{sen} \frac{\pi a}{2 W}\right)^{3}}{\cos \frac{\pi a}{2 W}}\right)\right]
$$

Tem-se então que:

$$
K_{I}=21.198 \mathrm{KN} \cdot \mathrm{cm}^{-3 / 2} \text {. }
$$

A seguir são apresentados os resultados numéricos dos Fatores de Intensidade de Tensão obtidos por meio das duas técnicas já citadas nesse trabalho e comparadas à solução analítica do problema em estudo.

\subsubsection{Técnica de Correlação dos Deslocamentos}

Inicialmente são calculados os Fatores de Intensidade de Tensões $\left(K_{I}^{\prime}\right)$ para o primeiro par de pontos fontes situado mais próximo da ponta da trinca e, repetem-se os cálculos, para os pontos fontes localizados na extremidade do elemento mais distante da ponta da trinca.

Feito isso, é realizada a média aritmética dos $K_{I}^{\prime}$ calculados, obtendo-se:

$$
K_{I}=21.185 K N . \mathrm{cm}^{-3 / 2} .
$$

O erro de aproximação em relação à solução analítica é de $0.06 \%$. 


\subsubsection{Técnica com base em tensões}

Com base na metodologia proposta por Maciel (2003), os Fatores de Intensidade de Tensão $\left(K_{I}^{\prime}\right)$ são calculados para três pontos situados à frente da trinca, tendo que:

$$
\begin{aligned}
& \left(K_{I}^{\prime}\right)_{\frac{a}{10}}=20.984 K N \cdot \mathrm{cm}^{-3 / 2} . \\
& \left(K_{I}^{\prime}\right)_{\frac{a}{9}}=21.193 \mathrm{KN} \cdot \mathrm{cm}^{-3 / 2} . \\
& \left(K_{I}^{\prime}\right)_{\frac{a}{8}}=21.429 \mathrm{KN} \cdot \mathrm{cm}^{-3 / 2} .
\end{aligned}
$$

Calculados os $K_{I}^{\prime}$ para os três pontos selecionados, obtém-se o valor de $K$ pela média aritmética desses pontos, dado por:

$$
K_{I}=21.202 K N \cdot \mathrm{cm}^{-3 / 2} \text {. }
$$

O erro de aproximação em relação à solução analítica é de $0.019 \%$.

Como forma de justificar a escolha pela metodologia de Maciel (2003), será apresentada, para esse problema, a técnica proposta por Paris\& Cañas (1997) para o cálculo do FIT.

Para determinação do FIT foi gerada, inicialmente, a curva de tensão de 25 pontos internos situados à frente da ponta da trinca e comparada à solução analítica (Figura 7.4). Além disso, foram utilizados 12 elementos quadráticos na discretização da trinca. 


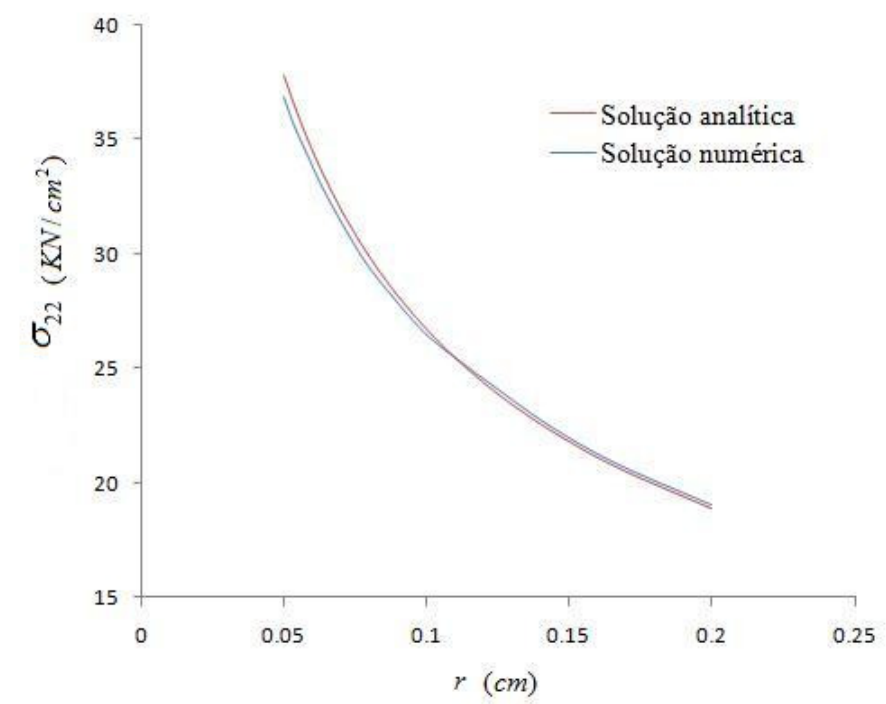

Figura 7.4: Campo de tensões em pontos próximos à ponta da trinca.

Com base na Figura 7.4, são calculados os $K_{I}^{\prime}$ por meio da eq. (4.10), para o caso em que $\theta=0$, obtendo-se:

$$
K_{I}=\sigma_{22} \sqrt{2 \pi r}
$$

Aplicando a função logarítmica em ambos os lados da eq. (7.2) e resolvendo para $\ln \left(\sigma_{22}\right)$, tem-se:

$$
\ln \left(\sigma_{22}\right)=\ln \left(\frac{K_{I}}{\sqrt{2 \pi}}\right)-0.5 \ln (r)
$$

A eq. (7.3) é a equação da reta podendo ser escrita na forma:

$$
\begin{aligned}
& \ln \left(\sigma_{22}\right)=c+b \ln (r) \\
& \text { sendo } c=\ln \left(\frac{K_{I}}{\sqrt{2 \pi}}\right) \text { e } b=-0.5
\end{aligned}
$$

A partir da eq. (7.3) pôde-se obter a distribuição de tensões em escala logarítmica, conforme Figura 7.5. 


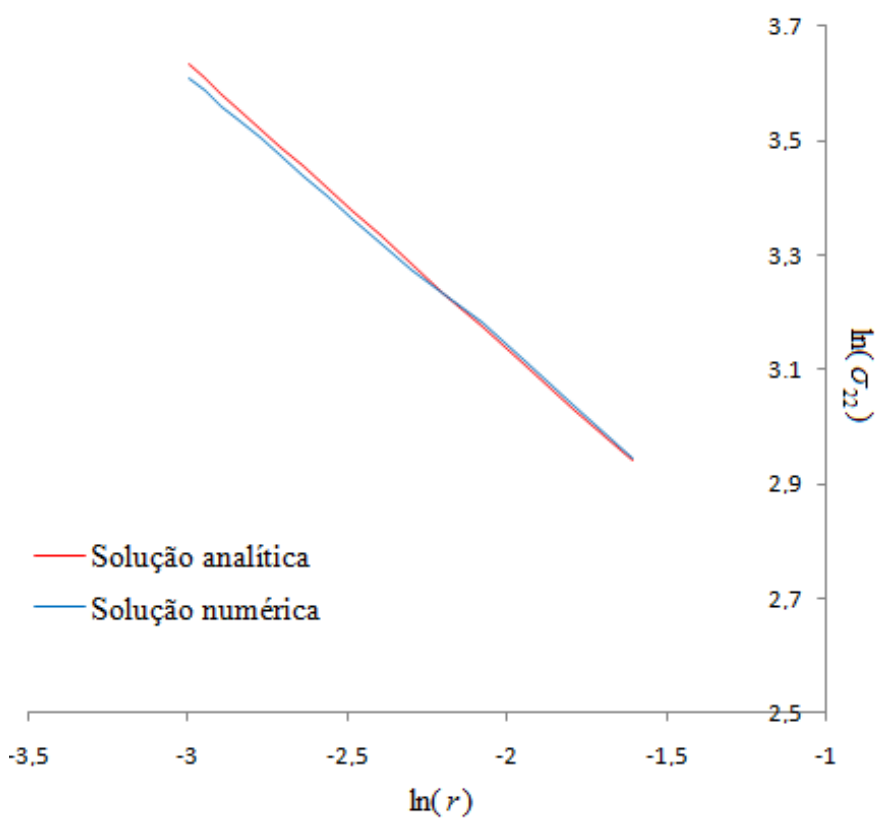

Figura 7.5: Gráfico das tensões em escala logarítmica.

Para o cálculo numérico de $K_{I}$, seleciona-se o trecho do gráfico onde os valores são aproximados por uma reta, conforme a solução analítica. Dessa forma, é possível determinar as constantes da reta, ou seja, ou valores de " $b "$ e " $c$ " da eq. (7.4).

Para esse exemplo o trecho que mais se aproxima da solução analítica é apresentado na Figura 7.6.

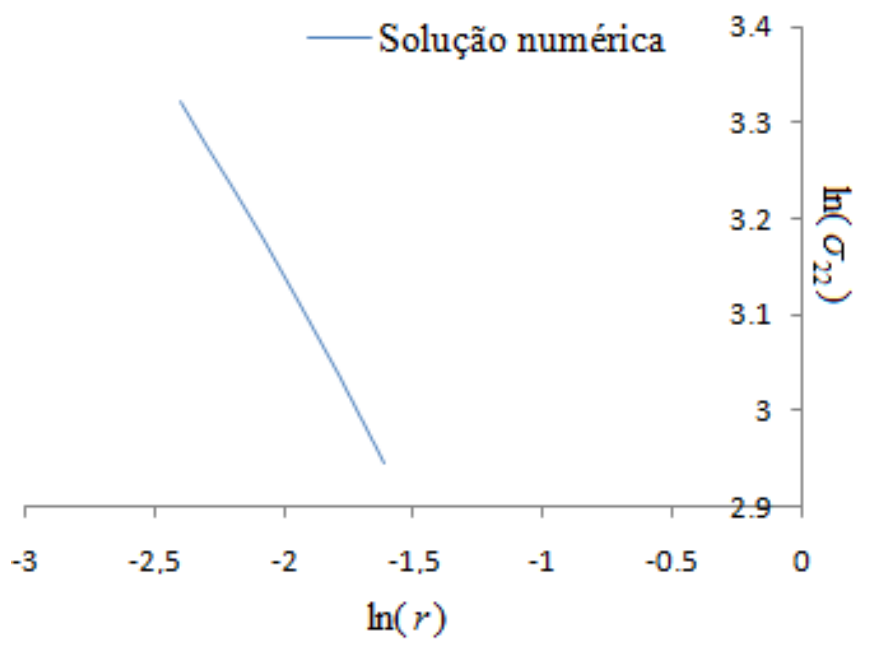

Figura 7.6: Trecho escolhido no gráfico logarítmico para obtenção de $K_{I}$. 
A partir da Figura 7.6 tem-se:

$b=-0.476$.

$c=2.184$.

Sendo assim, $K_{I}$ é dado por:

$$
\begin{aligned}
& 2.184=\ln \left(\frac{K_{I}}{\sqrt{2 \pi}}\right) \\
& K_{I}=22.276{\mathrm{KN} . \mathrm{cm}^{-3 / 2}} .
\end{aligned}
$$

O erro de aproximação em relação à solução analítica é de 5.08\%. Com esse resultado verifica-se que, para obter valores razoáveis do FIT, são necessários mais elementos para discretizar a trinca e muitos pontos internos para gerar as curvas de tensões em escala logarítmica. Sendo assim, escolheu-se a metodologia proposta por Maciel (2003), com base nas tensões, para obtenção do FIT.

\subsubsection{Problema com trinca central}

O problema analisado trata-se de uma chapa retangular, com uma trinca central, submetida a uma tensão uniforme (Figura 7.7). O problema apresenta as seguintes características:

Estado Plano de Tensão (EPT).

Coeficiente de Poisson: $v=0,2$.

Módulo de Elasticidade: $E=3000 \mathrm{KN} / \mathrm{cm}^{2}$.

Dimensões: $W=10 \mathrm{~cm}, L_{1}=10 \mathrm{~cm}, L_{2}=10 \mathrm{~cm}, 2 a=2 \mathrm{~cm}$.

Tensão aplicada: $\sigma=10 \mathrm{KN} / \mathrm{cm}^{2}$.

Abertura entre as faces da trinca: $\delta=210^{-3} a$. 


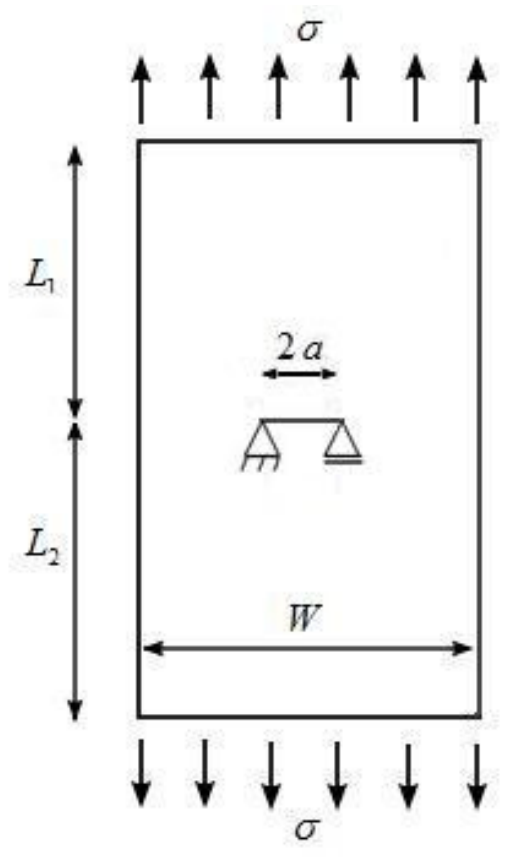

Figura 7.7: Chapa com trinca central.

Para a resolução numérica desse exemplo foram utilizados 42 elementos quadráticos, sendo 11 elementos quadráticos considerados para a discretização da trinca. A deformada para o problema é dada por (Figura 7.8):

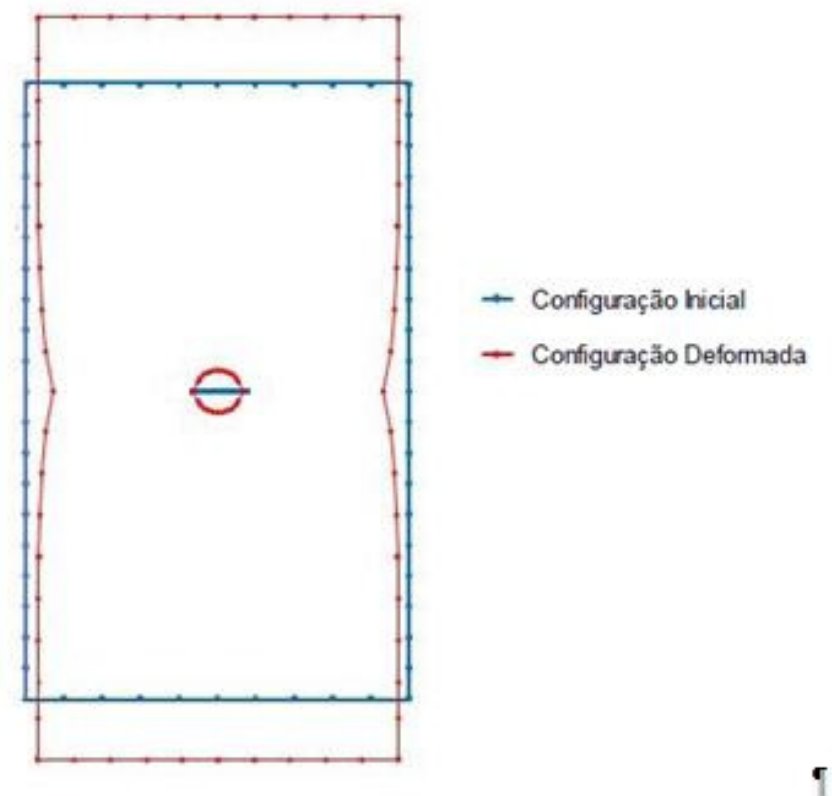

Figura 7.8: Configuração deformada da chapa com trinca central. 
De acordo com o trabalho de Tada et al. (2000), o valor de $K_{I}$ analítico obtido é:

$$
K_{I}=20.906 \mathrm{KN} \cdot \mathrm{cm}^{-3 / 2} \text {. }
$$

Por meio da técnica de correlação dos deslocamentos, o valor de $K_{I}$ é obtido:

$$
K_{I}=20.892 \mathrm{KN} \cdot \mathrm{cm}^{-3 / 2}
$$

O erro de aproximação em relação à solução analítica é de $0.07 \%$.

Considerando a técnica com base nas tensões, os valores do FIT para os três pontos internos são dados por:

$$
\begin{aligned}
& \left(K_{I}^{\prime}\right)_{\frac{a}{10}}=21.299 \mathrm{KN} \cdot \mathrm{cm}^{-3 / 2} . \\
& \left(K_{I}^{\prime}\right)_{\frac{a}{9}}=21.263 \mathrm{KN} \cdot \mathrm{cm}^{-3 / 2} . \\
& \left(K_{I}^{\prime}\right)_{\frac{a}{8}}=21.218 \mathrm{KN} \cdot \mathrm{cm}^{-3 / 2} .
\end{aligned}
$$

Fazendo-se a média aritmética desses três pontos obtém-se o FIT da trinca:

$$
K_{I}=21.149 \mathrm{KN} \cdot \mathrm{cm}^{-3 / 2} \text {. }
$$

O erro de aproximação em relação à solução analítica é de $0.29 \%$.

7.1.3 Problema com trinca de borda inclinada

O problema analisado trata-se de uma chapa retangular, com uma trinca de borda inclinada, submetida a uma tensão uniforme (Figura 7.9). No exemplo em questão é solicitado o Modo Misto (Modos I e II) de deformação. O problema apresenta as seguintes características:

Estado Plano de Tensão (EPT).

Coeficiente de Poisson: $v=0,2$. 
Módulo de Elasticidade: $E=3000 \mathrm{KN} / \mathrm{cm}^{2}$.

Dimensões: $W=10 \mathrm{~cm}, L_{1}=15 \mathrm{~cm}, L_{2}=10 \mathrm{~cm}, a=3 \mathrm{~cm}$.

Ângulo de orientação da trinca: $\theta=45^{\circ}$.

Tensão aplicada: $\sigma=10 \mathrm{KN} / \mathrm{cm}^{2}$.

Abertura entre as faces da trinca: $\delta=210^{-3} a$.

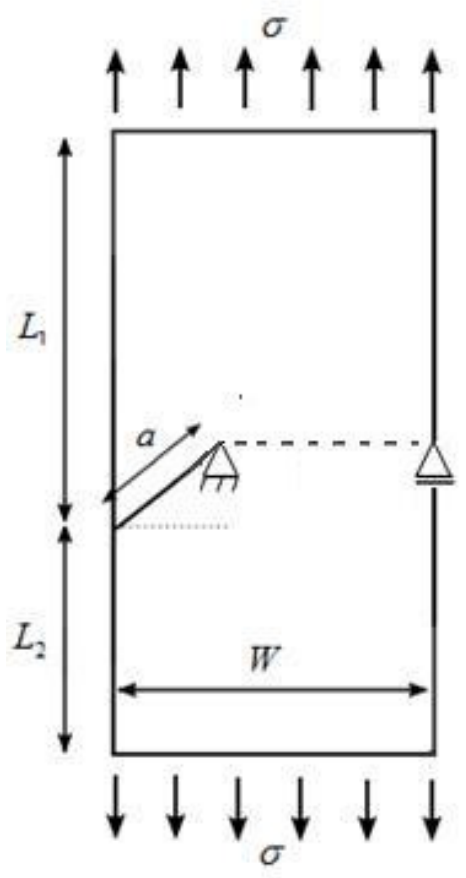

Figura 7.9: Chapa com borda inclinada.

Para a resolução numérica desse exemplo foram utilizados 50 elementos quadráticos, sendo 16 elementos quadráticos utilizados na discretização da trinca. A deformada para o problema é dada por (Figura 7.10): 


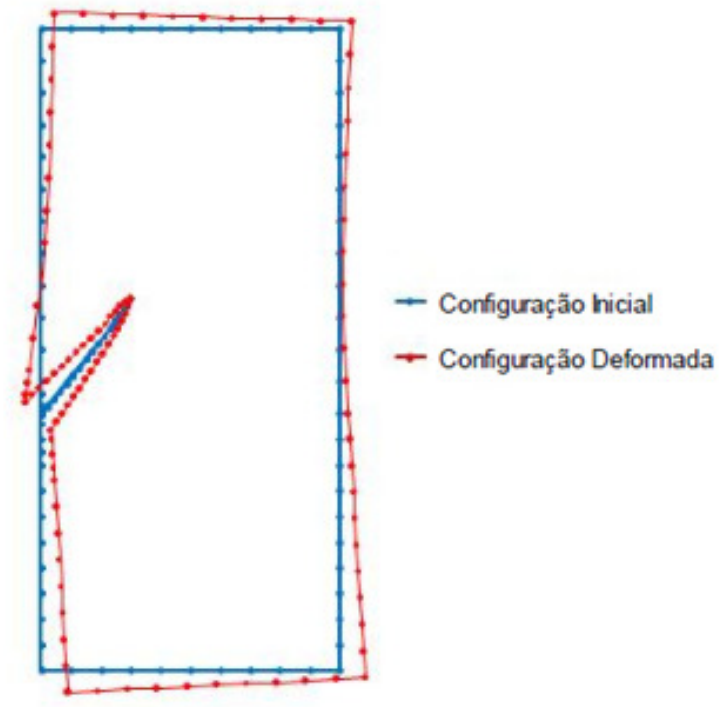

Figura 7.10: Deformada da chapa com trinca de borda inclinada.

Os valores de $K_{I}$ e $K_{I I}$ analíticos foram obtidos em Murakami (1987) sendo dados por:

$$
\begin{aligned}
& K_{I}=26.985 \mathrm{KN} . \mathrm{cm}^{-3 / 2} . \\
& K_{I I}=13.815 \mathrm{KN} . \mathrm{cm}^{-3 / 2} .
\end{aligned}
$$

$\mathrm{Na}$ tabela a seguir encontram-se os valores dos Fatores de Intensidade de Tensão obtidos numericamente comparados à solução analítica.

Tabela 7.1: Comparação entre o FIT numérico e analítico.

\begin{tabular}{|l|l|l|l|l|}
\hline $\begin{array}{c}\text { Técnicas numéricas para determinação do } \\
\text { FIT }\end{array}$ & $K_{I}$ & $\begin{array}{l}\text { Erro } \\
(\%)\end{array}$ & $K_{I I}$ & $\begin{array}{l}\text { Erro } \\
(\%)\end{array}$ \\
\hline Técnica de Correlação dos deslocamentos & 26.924 & 0.22 & 13.789 & 0.19 \\
\hline Técnica com base em tensões & 26.955 & 0.11 & 13.796 & 0.14 \\
\hline
\end{tabular}


7.2 Determinação da direção de crescimento da trinca

A direção da propagação das trincas é apresentada nesta seção. Os Fatores de Intensidade de Tensão, nesse estudo, são calculados por meio da técnica de correlação dos deslocamentos e o ângulo de propagação da trinca é obtido por meio do critério da Máxima Tensão Circunferencial.

\subsubsection{Problema com trinca central}

Neste exemplo é analisada a trajetória de propagação da trinca. Trata-se de uma chapa quadrada, com uma trinca central, submetida a um carregamento $\sigma=1.0 \mathrm{KN} / \mathrm{cm}^{2}$ (Figura 7.11). Para este modelo adotou-se $v=0.2, E=3000 \mathrm{KN} / \mathrm{cm}^{2}$, $L=200 \mathrm{~cm}, 2 a=20 \mathrm{~cm}$

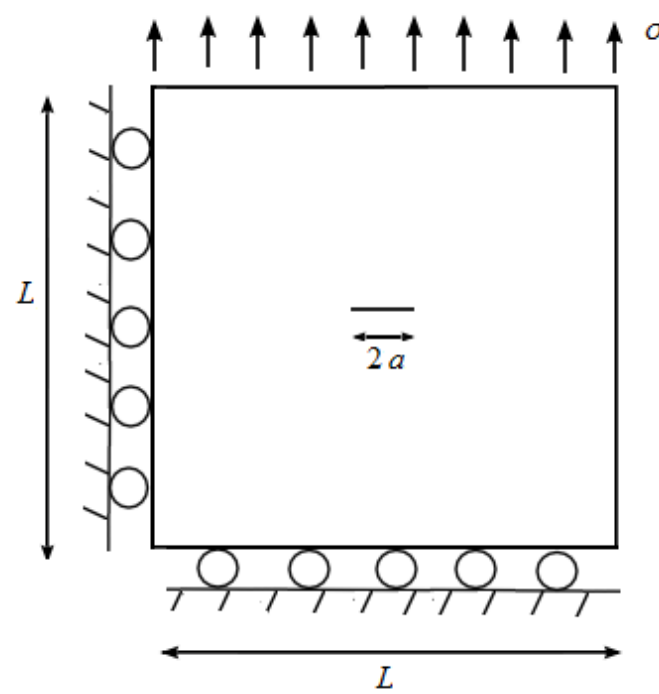

Figura 7.11: Chapa com trinca central. 
Neste modelo utilizou-se 58 elementos de contorno, sendo 20 utilizados para discretização da trinca.

A direção do crescimento da trinca pode ser obtida por meio de diferentes incrementos de propagação $(2.5 \mathrm{~cm}$ e $5 \mathrm{~cm})$, conforme Figura 7.12. A direção da propagação foi obtida utilizando o critério da Máxima Tensão Circunferencial. Sendo um problema em Modo I apenas, a trajetória da trinca satisfaz essa condição $(\theta=0)$, mantendo-se horizontal ao longo de cinco iterações.

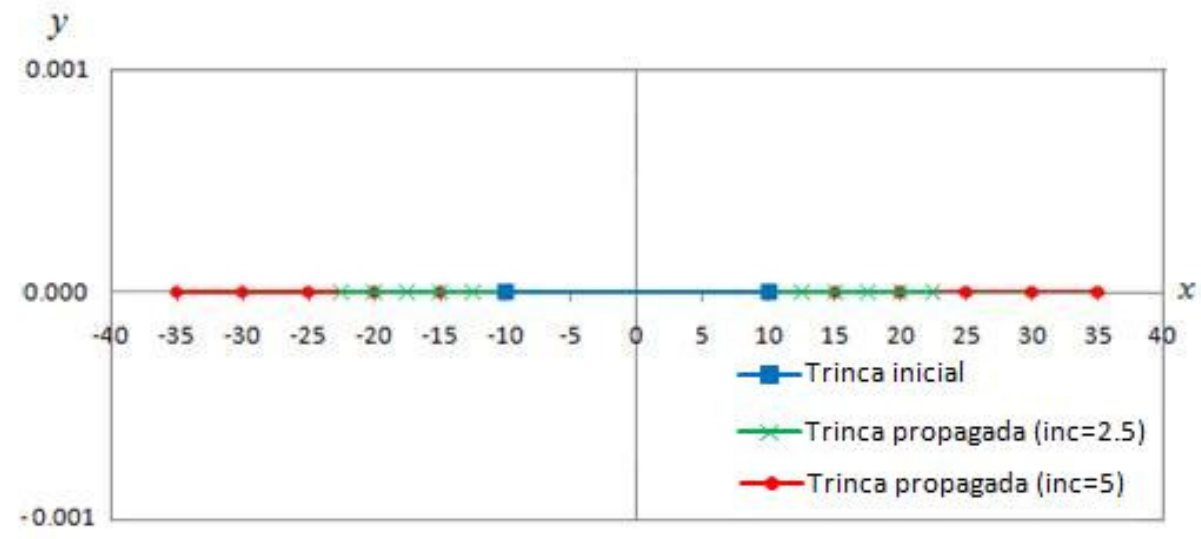

Figura 7.12: Trajetória de propagação da trinca.

Sendo uma chapa com carregamento unitário, determina-se a solução analítica para o problema: $K_{I}=\sqrt{\pi a}$ e $K_{I I}=0$. Sendo assim, é possível compará-la aos resultados numéricos encontrados a cada iteração para um incremento de $5 \mathrm{~cm}$ (Figura 7.13). Este resultado apresentou um erro em torno de $0.1 \%$ para $K_{I}$ e um erro absoluto na ordem de $10^{-6}$ para $K_{I I}$. Verifica-se, portanto, que os resultados obtidos foram satisfatórios. 


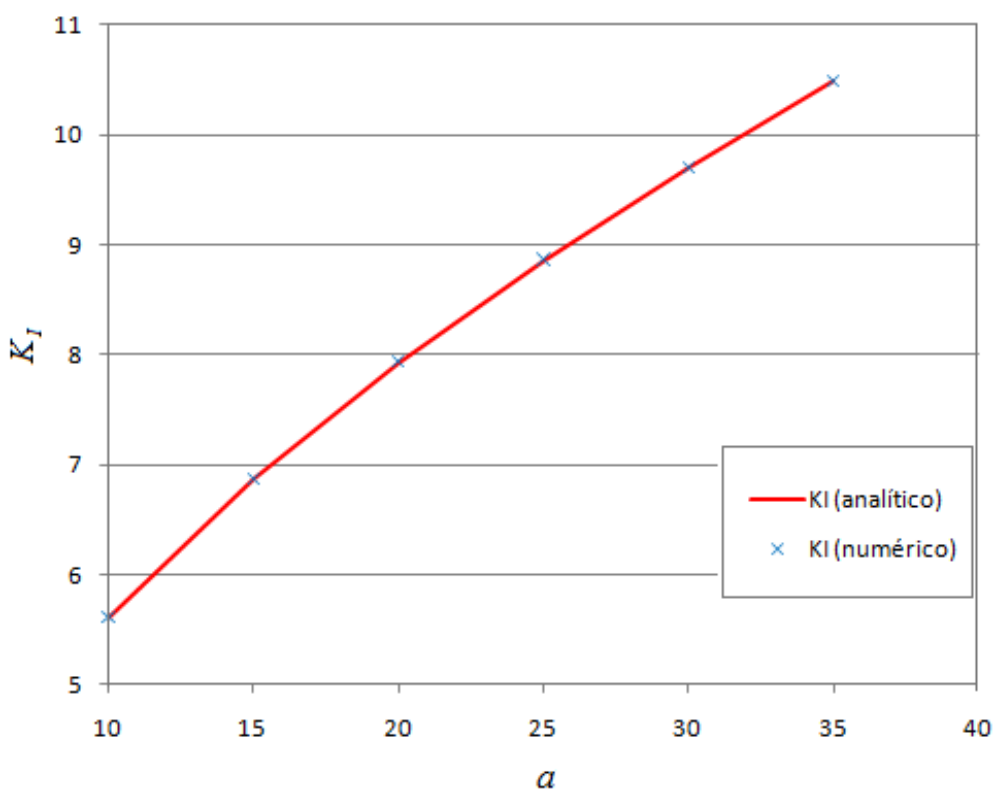

Figura 7.13: Comparação entre $K_{I}$ analítico e numérico.

7.2.2 Problema com trinca de borda

Este exemplo trata-se de uma chapa com uma trinca de borda horizontal, submetida a um carregamento $\sigma=10 \mathrm{KN} / \mathrm{cm}^{2}$ (Figura 7.14). O problema encontra-se inicialmente em Modo II puro de propagação. Os parâmetros adotados neste exemplo são $v=0.25, E=3000 \mathrm{KN} / \mathrm{cm}^{2}, 2 L=60 \mathrm{~cm}, a=L / 3$.

Para a discretização do problema utilizou-se 54 elementos de contorno, sendo 18 para a discretização da trinca. 


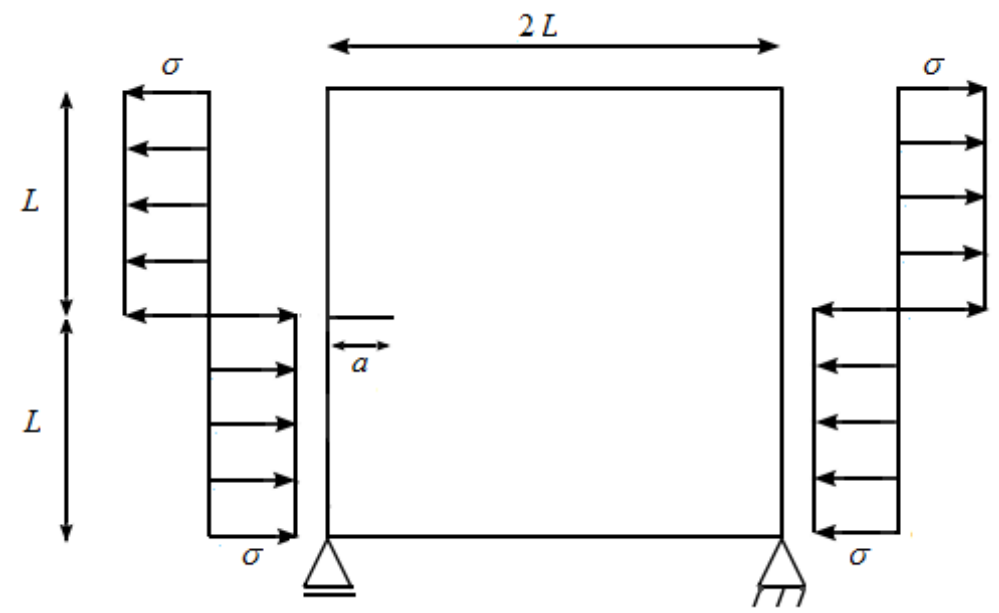

Figura 7.14: Chapa de borda horizontal.

Neste exemplo foi analisado o ângulo de propagação da trinca. Os resultados para o ângulo de propagação inicial foram comparados à Figura 7.15, a qual apresenta um gráfico com a relação do ângulo formado entre a inclinação da trinca e a direção do carregamento, em diferentes critérios de propagação.

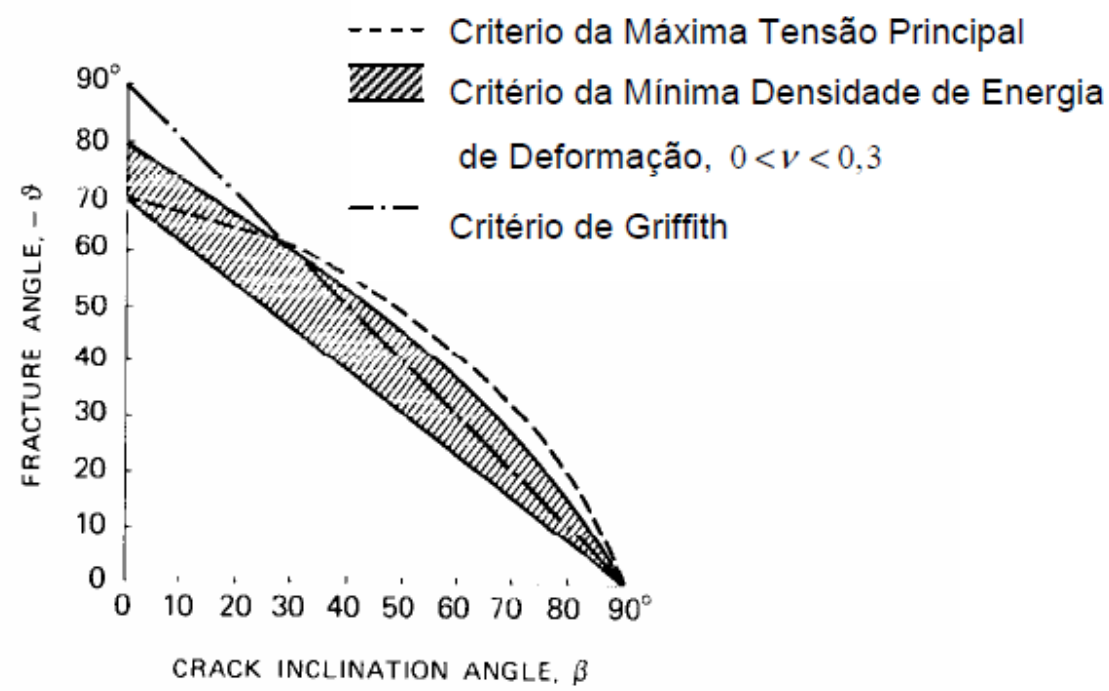

Figura 7.15: Direção da propagação da trinca (CARPINTERI, 1986).

Na Figura 7.15, $\beta$ é o ângulo formado entre a inclinação da trinca e a direção de aplicação do carregamento. Para o problema em estudo, o ângulo $\beta$ é igual a zero. De acordo com a Figura 7.15, a direção da propagação da trinca é dada entre $70^{\circ}$ e $90^{\circ}$ (eixo local na ponta da trinca). Por meio do critério da Tensão Máxima Circunferencial, o ângulo inicial 
(analítico) para este problema é de $70.5^{\circ}$. O ângulo obtido numericamente, utilizando este mesmo critério, é de $71.06^{\circ}$, apresentando um erro de $0.8 \%$. Este resultado está numa faixa aceitável pelo critério da mínima densidade de energia de deformação apresentando um erro de $21 \%$ ao critério de Griffith.

Na Figura 7.16 ilustra-se uma representação, com os ângulos de propagação obtidos, para o problema em Modo II.

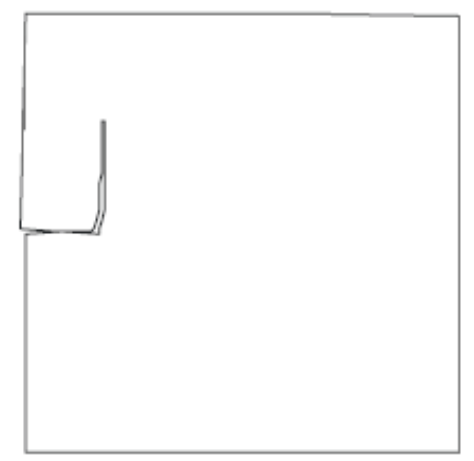

Figura 7.16: Direção de propagação da trinca para o Modo II.

Pela Figura 7.16 observa-se que inicialmente atua o Modo II puro, até que a trinca esteja aproximadamente a $90^{\circ}$ da original, onde passa a atuar (localmente) o Modo puro I, fazendo a trinca crescer nesta mesma direção até a ruptura total.

A trajetória de propagação da trinca considerando cinco incrementos de $2 \mathrm{~cm}$ é dada por (Figura 7.17). 


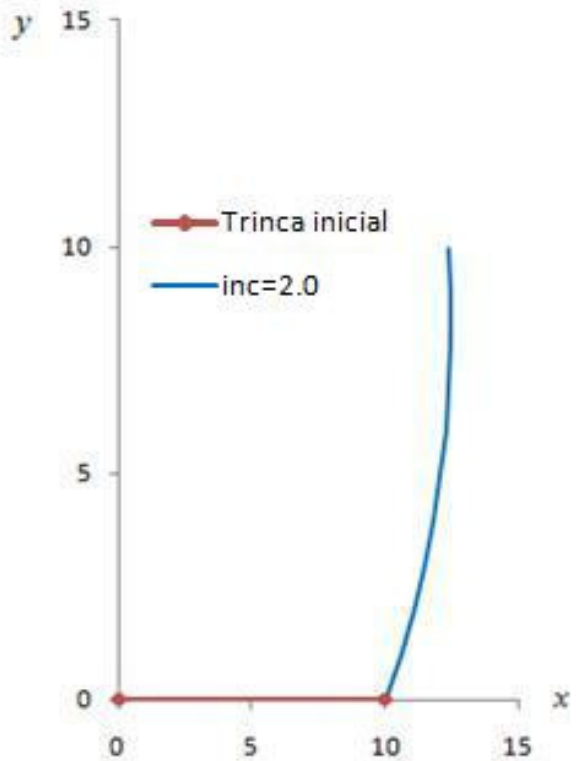

Figura 7.17: Configuração da trinca de borda propagada.

O resultado desse problema foi comparado ao obtido por Portela et al. (1993), onde encontrou-se a configuração propagada proposta neste trabalho próxima ao da referência (Figura 7.18).

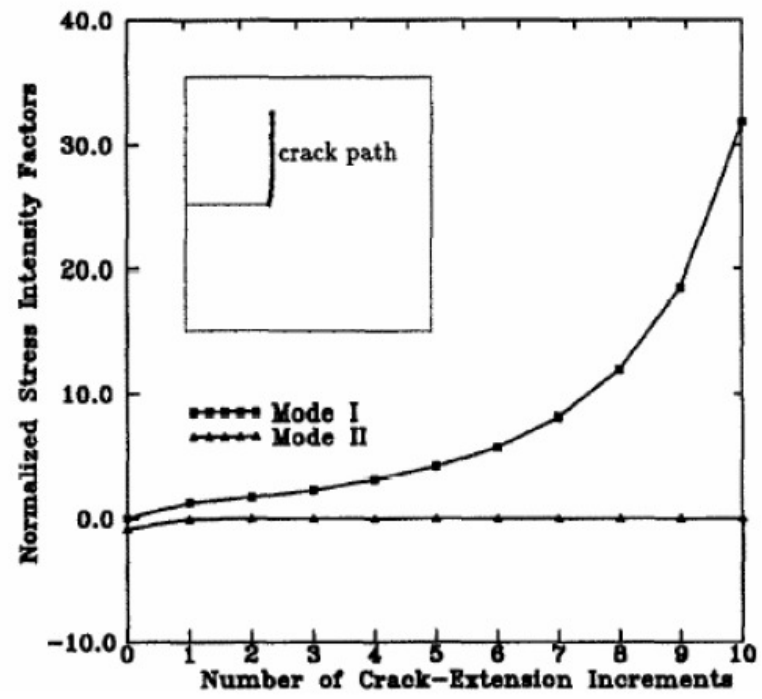

Figura 7.18: Trajetória de propagação do trabalho de Portela et al (1993). 


\section{CONCLUSÕES}

Nesse trabalho foram analisados problemas com trinca discreta usando o Método dos Elementos de Contorno. Nos problemas apresentados foram utilizadas metodologias para o cálculo do Fator de Intensidade de Tensão (FIT) e da direção do crescimento da trinca.

$\mathrm{Na}$ modelagem da trinca, a proximidade entre as faces da trinca leva ao surgimento de integrais quase singulares na formulação do MEC, prejudicando a solução do problema analisado. As perturbações geradas pela presença da quase singularidade podem conduzir ao mau condicionamento do sistema matricial, gerando erros numéricos satisfatórios.

A estabilidade (ou instabilidade) de um sistema fornece informações sobre a sensibilidade do cálculo numérico aos erros de arredondamento acumulados nos cálculos, assim como de pequenas variações das grandezas envolvidas nos problemas. Um sistema, por exemplo, é considerado estável quando pequenas perturbações nos dados de entrada conduzem a soluções próximas.

Para solucionar a questão da quase singularidade, que surge na formulação do MEC devido à análise da trinca discreta, foi utilizada uma técnica de integração a qual forneceu estabilidade numérica aos problemas analisados.

Resolvido o sistema matricial do MEC e obtidas as soluções no contorno, foi possível implementar técnicas para a determinação do FIT na ponta da trinca e a direção do crescimento da trinca.

Dentro dessa abordagem foi considerada, para a avaliação do FIT, a técnica de correlação dos deslocamentos e a técnica com base nas tensões em pontos internos à frente da trinca. Na técnica com base nas tensões, os três pontos internos considerados para obtenção do FIT apresentaram uma convergência mais rápida aos valores do FIT analítico.

A técnica de correlação dos deslocamentos e a técnica com base nas tensões apresentaram resultados precisos quando comparados à solução analítica, mostrando a precisão da técnica de integração utilizada e das metodologias empregadas para o cálculo do FIT. 
Além disso, foi analisada a direção na qual a trinca se propaga para dois modos de deformação (Modos I e II), utilizando o critério da Máxima Tensão Circunferencial. Observou-se, nos exemplos apresentados, resultados satisfatórios e uma pequena variação na discretização da malha de elementos de contorno da trinca devido ao seu crescimento.

De forma geral, pôde-se observar que o MEC mostrou-se uma ferramenta numérica adequada à modelagem da trinca discreta. As soluções são precisas mesmo usando pouca discretização nos modelos e poucos incrementos na análise da direção do crescimento da trinca.

Espera-se com esse trabalho estender os problemas de trinca discreta, utilizando o MEC, para casos tridimensionais. Além disso, sugere-se estender as análises para problemas de fadiga e considerar o estudo para materiais com diferentes comportamentos como os elasto-plásticos e os quase-frágeis. 


\section{REFERÊNCIAS BIBLIOGRÁFICAS}

ALIABADI, M. H. The boundary element method: applications in solids and structures. John Wiley \& Sons LTD, vol. 2, England, 2002.

ANDERSON, T. L. Fracture mechanics: fundamentals and applications. CRC Press, Inc., USA, 1995.

BECKER, A. A. The boundary element methods in engineering: a complete course. McGraw-Hill International (UK) Limited, 1992.

BITTENCOURT, T. N. Computer simulation of linear and nonlinear crack propagation in cementitious materials. Ph.D. Thesis, Cornell University, USA, 1993.

BITTENCOURT, T. N.; MIRANDA, A. C. O.; MEGGIOLARO, M. A.; CASTRO, J. T. P.; MARTHA, L. F. Fatigue life and crack path predictions in generic $2 \mathrm{D}$ structural components. Engineering Fracture Mechanics, V. 70, 1259 -1279.

BLANDFORD, G. E.; INGRAFFEA, A. R.; LIGGET, J. A. Two dimensional stress intensity factor computations using the boundary element method. Int. J. Num. Meth. Engn., V.17, 387-404, 1981.

BREBBIA, C.A.; DOMINGUES, J. Boundary element method: an introductory course. Southampton: Comp. Mech. Publications, 1989.

BROEK, D. Elementary engineering fracture mechanics. Kluwer Academic Publishers, Dordrecht, 1986.

BROEK, D. The practical use of fracture mechanics. Kluwer Academic Publishers, USA, 1989. 
CARPINTERI, A. Mechanical damage and crack growth in concrete. Martinus Nijhoff Publishers, Dordrecht, The Netherlands, 1986.

CEN, Z.; MAIER, G. Bifurcations and instabilities in fracture of cohesive softening structures: a boundary element analysis. Fatigue Fract. Engn. Mater., V.15, 911-928, 1992.

CRUSE T. A. Surface cracks: physical problems and computational solutions. J. L. Swedlow (ed.), American Society of Mech. Engineers, New York, 153-170, 1972.

CRUSE T. A.; VAN BUREN, W. Three dimensional elastic stress analysis of a fracture specimen with an edge crack. Int. Journal Mech., V.7, 1-15. 1971.

DUMONT, N. A.; NORONHA, M. A. M. A simple scheme for the numerical evaluation of integrals with complex singularity poles. Comp. Mech, v.22, p.42-49, 1998.

EWALDS H. L.; WANHILL R. J. H. Fracture mechanics. Arnold Edition, London, UK, 1984.

ERDOGAN, F.; SIH, G. C. On the crack extension in plates under plane loading and transverse shear. ASME J. Basic Engn., V.85, 519-527, 1963.

GAUL, L.; KOGL M.; WAGNER M. Boundary element methods for engineers and scientists: an introductory course with advanced topics. Springer, 2003.

GRAY, L .J.; MARTHA L. F.; INGRAFFEA, A. R. Hyper singular integrals in boundary element fracture analysis. Int. J. Num. Meth. Eng., V.29, 1990.

GRIFFITH, A. A. The phenomena of rupture and flow in solids. Phil. Trans. Roy. Soc. Series A., Vol. 221, pp. 163-197, 1920. 
GUILBAULT R.; LALONDE, S. Finite separation method: an efficient boundary element crack modeling technique. Comp. Mech., 2009.

IRWIN, G. R. Analysis of stresses and strains near the end of a crack traversing a plate. Trans. ASME J. Appl. Mech., vol. 24, p. 361-364, 1957.

LIANG, R. Y.; LI Y. N. Simulations of non-linear fracture process zone in cementitious material a boundary element approach. J. Computational Mechanics, 7, p. 413-427, 1991.

MACIEL, D. N. Determinação dos fatores de intensidade de tensão estáticos e dinâmicos via MEC com integração analítica em coordenadas locais. Dissertação (mestrado) - Escola de Engenharia de São Carlos, Universidade de São Paulo, São Carlos, 2003.

MI, Y. Three dimensional analysis of crack growth. Topics in Engineering, V. 28, Comp. Mech. Publications, 1996.

MURAKAMI Y. Stress intensity factors handbook. Pergamon, Oxford, 1987.

NORONHA, M. A. M.; Técnicas avançadas de integração numérica e programação orientada a objetos aplicadas a métodos de elementos de contorno. Tese (doutorado) Pontifícia Universidade Católica do Rio de Janeiro, Rio de Janeiro, 1998.

PARIS, F.; CAÑAS, J. Boundary element method fundamentals and applications. Oxford, Oxford University Press, 1997.

PEREIRA, A.M.B. Avanços na visualização, análise não-linear e programação com o método dos elementos de contorno. Dissertação (mestrado) - Escola Politécnica, Universidade de São Paulo, São Paulo, 2004.

PORTELA, A.; ALIABADI, M. H.; ROOKE, D. P. Dual boundary element incremental analysis of crack propagation. Computer \& Structures, v. 46, n. 2, pp. 237-247, 1993. 
PORTELA, A.; MATOS, P. F. P.; MOREIRA, P. M. G. P.; CASTRO, P. M. S. T. Dual boundary element analysis of cracked plates: post -processing implementation of the singularity subtraction technique. Computers and Structures, V. 82, 1443-1449, 2004.

SAOUMA, V. Fracture mechanics lecture notes. Dept. of Civil Environmental and Architectural Engineering, University of Colorado, Boulder, USA, 2000.

SIH, G. C. Handbook of stress intensity factor. Institute of Fracture and Solid Mechanics, Lehigh University, 1973.

SNYDER, M. D.; CRUSE, T. A. Boundary integral equation analysis of cracked anisotropic plates. Int. J. Fracture, V.11 315-328, 1975.

TADA, H.; PARIS, P. C.; IRWIN, G. R. The stress analysis of cracks handbook. New York, ASME Press, 2000.

TELLES, J. C. F.; GUIMARÃES, S. Green's function: a numerical generation for fracture mechanics problems via Boundary Elements. Comput. Meth. Appl. Mech. Engn., 188, p.847$858,2000$.

TELLES, J. C. F.; GUIMARÃES, S.; SILVEIRA, N. P. P. A numerical Green's function BEM formulation for crack growth simulation, engineering analysis with boundary elements. V. 29, 978-985, 2005.

TIMOSHENKO, S. P.; GOODIER, J. N. Teoria da elasticidade. Ed. Guanabara Dois S. A., $3^{\mathrm{a}}$ edição, Rio de Janeiro, 1980.

WATSON, J. O. Hermitian cubic and singular element for plate strain. Developments in Boundary Element Methods 4. Elsevier Applied Science Publ. 1-28, 1986.

WESTERGAARD, H. M. Bearing pressures and cracks. J. Appl. Mechanics n.6 49-53, 1939.

ZAGOTTIS, D. Fundamentos da teoria das estruturas. São Paulo, 1983. 
